\title{
LAS MEDIDAS PROVISIONALES Y CAUTELARES EN \\ LOS PROCEDIMIENTOS DE RESTITUCIÓN DE MENORES: ANÁLISIS DEL REGLAMENTO (UE) 2019/1111 EN CONEXIÓN CON EL ORDENAMIENTO JURÍDICO ESPAÑOL
}

\author{
PROVISIONAL AND PROTECTIVE MEASURES IN CHILD \\ RETURN PROCEDURES: ANALYSIS OF REGULATION (EU) \\ 2019/1111 IN CONECTION WITH THE SPANISH LEGAL SYSTEM
}

\author{
Antonio Jesús Calzado Llamas \\ Investigador Predoctoral \\ Universidad de Sevilla
}

Recibido: 15.12.2020 / Aceptado: 14.01.2021

DOI: https://doi.org/10.20318/cdt.2021.5953

Resumen: El presente artículo abarca el régimen de medidas provisionales, incluidas las cautelares en los procedimientos de restitución de menores con arreglo al nuevo régimen del Reglamento 2019/1111. Comenzando por el análisis de su artículo 15, nos centramos en su aplicación en dos momentos procesales a resultas de un traslado o retención ilícitos: el mantenimiento del contacto con el progenitor custodio durante el procedimiento y las medidas de protección contra cualquier grave riesgo en caso de devolución al Estado de residencia habitual. Se aprovecha la ocasión para evaluar la articulación de las reformas europeas con la legislación española. Finalmente, tomamos en consideración la existencia de medidas preventivas en el Derecho convencional, europeo y nacional para evitar la sustracción internacional de menores.

Palabras clave: sustracción internacional de menores, Reglamento 2019/1111, Convenio de La Haya de 1980, medidas provisionales y cautelares, medidas preventivas.

Abstract: The present article encompasses the study of provisional, including protective measures in children return procedures according to the new Regulation (EU) 2019/1111 regime. Beginning with the analysis of its article 15, we focus on its application in two procedural moments as a result of an illegal removal or retention: the maintenance of contact with the custodial parent, and protective measures against any grave risk in case of return to the State of habitual residence. The occasion is seized to evaluate the linkage of European recasts with the Spanish legislation. Finally, we take into consideration the existence of preventive measures in conventional, European and national Law in order to avoid international child abduction.

Keywords: international child abduction, Regulation 2019/1111, 1980 Hague Convention, provisional and protective measures, preventive measures.

Sumario: I. Introducción. 1. El proceso de reforma del R. 2019/1111: en especial, su incidencia en los procedimientos de restitución de menores. 2. La relación entre el CH 80 y el R. 2019/1111. 3. Contextualización normativa del objeto de estudio: el régimen de medidas provisionales, incluidas las cautelares en los procedimientos de restitución de menores. II. La reforma del R. 2019/1111 en relación al régimen general de adopción de medidas provisionales, incluidas las cautelares: el artí- 
culo 15 R. 2019/1111. 1. Los requisitos para su adopción en defecto de competencia sobre el fondo del asunto. 2. La comunicación entre órganos jurisdiccionales y Autoridades Centrales. 3. La nueva ubicación del art. 15 R. 2019/1111 y sus repercusiones: en especial, el tránsito de la eficacia extraterritorial general de la Propuesta a la excepcional del nuevo Reglamento. III. Las medidas provisionales, incluidas cautelares en el procedimiento de restitución de menores. 1. Medidas durante el procedimiento: en especial, el contacto del menor con el progenitor (art. 27.2 R. 2019/1111). 2. Medidas en caso de dictarse la restitución del menor (art. 27.5 R. 2019/1111). IV. ¿Existen medidas preventivas de la sustracción internacional de menores? 1. Recomendaciones para la prevención de la sustracción internacional de menores a nivel convencional. 2. La prevención de la sustracción internacional de menores en la Unión Europea. 3. Las medidas preventivas en la legislación española. V. Conclusiones.

\section{Introducción}

1. La entrada en vigor del Reglamento (UE) 2019/1111, del Consejo, de 25 de junio de 2019, relativo a la competencia, el reconocimiento y la ejecución de resoluciones en materia matrimonial y de responsabilidad parental, y sobre la sustracción internacional de menores ${ }^{1}$ (en adelante, R. 2019/1111), nos invita, hasta su efectiva aplicación, a examinar cómo responde esta nueva norma europea a los problemas jurídicos que habían puesto de manifiesto tanto la doctrina como la jurisprudencia a raíz de la aplicación de su antecesor, el Reglamento (CE) 2201/2003 del Consejo, de 27 de noviembre de 2003, relativo a la competencia, el reconocimiento y la ejecución de resoluciones judiciales en materia matrimonial y de responsabilidad parental, por el que se deroga el Reglamento (CE) $n^{\circ} 1347 / 2000^{2}$ (en adelante, R. 2201/2003).

2. Observando simplemente las diferencias de extensión entre el futuro Reglamento y el aún vigente -pasando de 33 a 98 Considerandos, de 72 a 105 artículos y de 6 a 10 Anexos- cabe prever que dicho esfuerzo analítico será complejo $\mathrm{y}$, de hecho, está dando lugar ya a abundantes trabajos divulgativos y académicos. Lo ideal para su comprensión sería una tarea de análisis particular de los diferentes cambios en profundidad para, finalmente, contribuir a un entendimiento holístico del R. 2019/1111. Con tal propósito, el objetivo del presente trabajo es analizar un aspecto concreto: las medidas provisionales, incluidas las cautelares.

3. La Reforma ha incidido especialmente sobre los procedimientos de restitución de menores, complementando al Convenio sobre aspectos civiles de la sustracción internacional de menores, hecho en La Haya el 25 de octubre de $1980^{3}$ (en adelante, $\mathrm{CH}$ 80). Entre las normas que el legislador europeo anexa al procedimiento convencional, se incluye un régimen especial dedicado a estas medidas, que será objeto de nuestro estudio. Del mismo modo, nos proponemos evaluar si la normativa procesal española vigente se alinea con las nuevas reglas europeas en la materia. Por último, ofreceremos una reflexión en torno a la existencia de medidas preventivas contra la sustracción internacional de menores.

4. Pero, como veníamos diciendo, la llegada del R. 2019/1111, tras más de diez años de aplicación del aún vigente R. 2201/2003, nos exige una previa presentación a través de un breve examen del proceso legislativo del cual la nueva norma es resultado, así como una contextualización normativa del objeto de nuestro estudio.

\footnotetext{
${ }^{1}$ DOUE L 178 de 2 de julio de 2019.

${ }^{2}$ DOUE L 338 de 23 de diciembre de 2003.

${ }^{3}$ BOE núm. 202, de 24 de agosto de 1987. El pasado 25 de octubre de 2020, el Convenio cumplió su cuadragésimo aniversario, y con ocasión de ello, se han publicado dos estudios que hacen balance de la aplicación de este instrumento internacional y de las necesidades pendientes de abordar. Vid. A. DE RUITER. "40 years of The Hague Convention on child abduction: legal and societal changes in the rights of a child" PE 660. 559 recuperado de: http://www.europarl.europa.eu/thinktank/en/document. html?reference= IPOL_IDA(2020)660559; M. FreEman. "The Child Perspective in the Context of the 1980 Hague Convention". Policy Department for Citizens' Rights and Constitutional Affairs Directorate-General for Internal Policies. PE 659.819 -October 2020, recuperado de: https: //www.europarl.europa.eu/RegData/etudes/IDAN/2020/659819/IPOL_IDA(2020)659819_EN.pdf
} 


\section{El proceso de reforma del R. 2019/1111: en especial, su incidencia en los procedimientos de res- titución de menores}

5. Lo primero que cabe decir es que la propuesta de mejora que ha dado lugar al R. 2019/1111 sucede en el tiempo a una Propuesta anterior, de 17 de julio de $2006^{4}$, que incidía sobre cuestiones de competencia y ley aplicable al divorcio, la separación y la nulidad matrimonial. Se trató de un primer intento de reforma del R. 2201/2003 que no tuvo éxito, por la falta de unanimidad requerida en los asuntos de Derecho de Familia, si bien es cierto que, posteriormente, las cuestiones de ley aplicable fueron objeto de tratamiento en el Reglamento 1259/2010 (conocido como Roma III), dentro del marco de la cooperación reforzada. No interesa detenerse mucho más en esta iniciativa, pues no se abarcaron medidas de reforma más allá de los aspectos matrimoniales.

6. El 17 de abril de 2014 la Comisión publica un Informe sobre la aplicación del R. 2201/20035. En él, propuso revisar sus normas, ante la existencia de aspectos controvertidos en su aplicación. En relación con el procedimiento de restitución de menores, se denunciaba el incumplimiento del plazo de seis semanas de duración establecido por el CH 80 para llegar a una resolución sobre la devolución o no del menor. También se planteó la posibilidad de mejorar las normas del Reglamento mediante la incorporación de la doctrina del TJUE y el desarrollo de estándares mínimos sobre la audiencia al menor, ante el tratamiento tan heterogéneo de esta garantía en los Estados Miembros.

7. El proceso de reforma siguió con la publicación de la Propuesta de Reglamento del Consejo relativo a la competencia, el reconocimiento y la ejecución de resoluciones en materia matrimonial y de responsabilidad parental, y sobre la sustracción internacional de menores (refundición) ${ }^{6}$, que introduce el Capítulo III, sobre el proceso de retorno de menores, y la Sección $4^{\mathrm{a}}$ del Capítulo IV, que hace extensibles las disposiciones sobre reconocimiento y ejecución a las resoluciones sobre restitución y a sus medidas cautelares. Además, se modifican e incluyen varios Considerandos de apoyo interpretativo.

8. Junto a la Propuesta de Reforma, se presenta el Informe de Evaluación de Impacto de 30 de junio de $2016^{7}$, donde se ofrece una valoración de las diversas líneas de actuación planteadas para mejorar el R. 2201/2003. En resumidas cuentas, se abogaba por mantener el régimen vigente para crisis matrimoniales, y se proponían cambios normativos concernientes a la responsabilidad parental, la eficacia extraterritorial de resoluciones y la cooperación de autoridades ${ }^{8}$.

9. El campo de mayor atención fue la sustracción internacional de menores. En opinión de la Comisión, resultaba necesario adoptar varias medidas para mejorar la eficiencia y rapidez del procedimiento de retorno entre Estados Miembros. Esas medidas incluían: a) la concentración jurisdiccional; b) la eficacia extraterritorial de las medidas cautelares dictadas por las autoridades del Estado de retención; c) la concreción separada de los plazos procedimentales en primera y segunda instancia, e igualmente, para las Autoridades Centrales; d) la limitación a uno solo de recursos contra las decisiones sobre el retorno; y e) la posibilidad de ejecución provisional ${ }^{9}$.

\footnotetext{
${ }^{4}$ Comisión Europea. "Propuesta de Reglamento del Consejo por el que se modifica el Reglamento (CE) n 2201/2003 por lo que se refiere a la competencia y se introducen normas relativas a la ley aplicable en materia". Bruselas, 17.7.2006 COM(2006) 399 final - 2006/0135 (CNS).

${ }^{5}$ Comisión Europea. "Informe de 15 de abril de 2014 de la Comisión al Parlamento Europeo, al Consejo y al Comité Económico y Social Europeo sobre la aplicación del Reglamento (CE) núm. 2201/2003 del Consejo relativo a la competencia, el reconocimiento y la ejecución de resoluciones judiciales en materia matrimonial y de responsabilidad parental, por el que se deroga el Reglamento (CE) núm. 1347/2000” COM(2014) 225 final.

${ }^{6} \mathrm{COM} / 2016 / 0411$ final - 2016/0190 (CNS).

${ }^{7}$ Comisión Europea. "Commission Staff Working Document Impact Assessment accompanying the document Proposal for a Council Regulation on jurisdiction, the recognition and enforcement of decisions in matrimonial matters and the matters of parental responsibility, and on international child abduction (recast)". SWD/2016/0207 final - 2016/0190 (CNS).

${ }^{8}$ Vid. ibid. pp. 78-79, para un resumen de las propuestas de actuación para reformar el R. 2201/2003.

${ }^{9}$ Vid. ibid., p. 79.
} 
10. La Propuesta de la Comisión recibe el beneplácito del Consejo Económico y Social Europeo en su Dictamen de 21 de abril de $2017^{10}$. Posteriormente, el Parlamento Europeo en su Resolución legislativa de 18 de enero de 2018 planteó algunas interesantes enmiendas relacionadas, directa o indirectamente, con el procedimiento de restitución, tales como la previsión de la circunstancia de violencia de género o el amplio desarrollo que se propuso sobre el art. 20 de la Propuesta (aplicable por remisión del artículo 24), a fin de garantizar unas mínimas normas comunes de garantía de la posibilidad del menor de ser escuchado ${ }^{11}$.

11. En el Consejo Europeo, la Propuesta de la Comisión fue objeto de debates que centraron su interés en cuestiones como la audiencia al menor, las medidas provisionales y cautelares, el papel y la financiación de las Autoridades Centrales, el acogimiento del menor o la supresión del exequátur. Resultado de ello, se aprueban unas Orientaciones Generales el 3 de diciembre de $2018^{12}$, donde el Consejo da cuenta de aquellos debates, presenta sus conclusiones y propone varias modificaciones, supresiones y añadidos al texto legislativo de la Propuesta presentada en 2016.

12. Estas modificaciones son aprobadas por el Parlamento Europeo el 14 de marzo de $2019^{13}, \mathrm{y}$ tras ciertas revisiones puntuales, finalmente, el Consejo adopta una versión definitiva de su refundición el 24 de junio de $2019^{14}$ (el actual R. 2019/1111), que es aprobada por unanimidad el 25 de junio de $2019^{15}$. Este nuevo Reglamento comenzará a aplicarse de forma efectiva a partir del 1 de agosto de 2022.

\section{La relación entre el CH 80 y el R. 2019/1111: más allá de lo procedimental}

13. El R. 2019/1111, como viene siendo habitual en otros Reglamentos europeos, destina algunas disposiciones finales a concretar la relación con otros instrumentos cuyos ámbitos de aplicación coinciden, para disipar dudas en caso de solapamiento. Entre esas disposiciones, el art. 96 R. 2019/1111 consagra la relación de complementariedad entre el Reglamento y el Convenio. Esta complementariedad es reiterada en el art. 1.3 R. 2019/1111, y se observa que ambos artículos corrigen cierto punto de imprecisión del que adolecía el art. 60.e) R. 2201/2003, que enunciaba la relación entre ambos textos internacionales como de simple prevalencia del Reglamento frente al Convenio. Del nuevo texto se concluye que los Estados Miembros aplican de base el $\mathrm{CH}$ 80, pero complementado principalmente con las normas de los Capítulos III y IV.

${ }^{10}$ Comité Económico y Social Europeo. "Dictamen del Comité Económico y Social Europeo sobre la «Propuesta de Reglamento del Consejo relativo a la competencia, el reconocimiento y la ejecución de resoluciones en materia matrimonial y de responsabilidad parental, y sobre la sustracción internacional de menores (refundición)", COM (2016) 411 final — 2016/019 (CNS)] (2017/C 125/06), DOUE núm. C 125/46 de 21 de abril de 2017. El CESE realizó una valoración positiva de las medidas de mejora del Reglamento, pero planteó la necesidad de prever soluciones en caso para situaciones vinculadas con terceros Estados.

${ }^{11}$ Parlamento Europeo. Resolución legislativa de 18 de enero de 2018, sobre la propuesta de Reglamento del Consejo relativo a la competencia, el reconocimiento y la ejecución de resoluciones en materia matrimonial y de responsabilidad parental, y sobre la sustracción internacional de menores (refundición) (COM(2016)0411 - C8-0322/2016 - 2016/0190(CNS))”. En especial, vid. Enmiendas 11, 12, 13, y 44.

${ }^{12}$ Consejo Europeo. "Propuesta de Reglamento del Consejo relativo a la competencia, el reconocimiento y la ejecución de resoluciones en materia matrimonial y de responsabilidad parental, y sobre la sustracción internacional de menores (refundición)”. ST 147842018 INIT.

${ }^{13}$ Parlamento Europeo. Resolución legislativa del Parlamento Europeo, de 14 de marzo de 2019, sobre la propuesta de Reglamento del Consejo relativo a la competencia, el reconocimiento y la ejecución de resoluciones en materia matrimonial y de responsabilidad parental, y sobre la sustracción internacional de menores (versión refundida) (15401/2018 - C8-0023/2019 - 2016/0190(CNS)). TA/2019/0206.

${ }^{14}$ Consejo EuRopeo. "Reglamento de Ejecución relativo a la competencia, el reconocimiento y la ejecución de resoluciones en materia matrimonial y en materia de responsabilidad parental, y sobre la sustracción internacional de menores". ST 8214 2019 REV 3.

${ }^{15}$ Consejo Europeo. "Resultado de la votación. Reglamento del Consejo relativo a la competencia, el reconocimiento y la ejecución de resoluciones en materia matrimonial y de responsabilidad parental, y sobre la sustracción internacional de menores (refundición). Adopción del acto legislativo Sesión n. ${ }^{\circ} 3703$ del Consejo la Unión Europea (Transporte, Telecomunicaciones y Energía) Luxemburgo, 25 de junio de 2019”. ST 106502019 INIT. 
14. Más concretamente, el núcleo de la interacción entre el CH 80 y el R. 2019/1111 se concentra en el Capítulo III R. 2019/1111, que aúna en su articulado todas aquellas reglas que se anexan al procedimiento prefigurado en el Convenio de La Haya sobre sustracción internacional de menores. Es de elogiar que estas reglas se hayan ubicado en un Capítulo autónomo en el nuevo Reglamento, frente a la incómoda posición del anterior art. 11 R. 2201/2003, situado entre las normas de competencia judicial internacional sin tener tal carta de naturaleza.

15. Este nuevo Capítulo consagra algunas novedades, tales como la tramitación urgente de las solicitudes de retorno por las Autoridades centrales (art. 23 R. 2019/1111); la ampliación a seis semanas por cada instancia para pronunciarse sobre la restitución (art. 24 R. 2019/1111); el uso de la mediación como forma de solventar la sustracción ilícita, entre otros mecanismos alternativos (art. 25 R. 2019/1111); la aplicación del artículo 21 sobre el derecho del menor a ser oído (art. 26 R. 2019/1111); las previsiones sobre medidas cautelares durante y después del procedimiento de restitución, que analizaremos en este trabajo (art. 27. 2 y 5 R. 2019/1111); la aclaración sobre la carga de la prueba de la adopción de medidas contra el grave peligro para el menor en la persona que solicita el retorno (art. 27.3 R. 2019/1111); y la comunicación directa entre órganos jurisdiccionales y Autoridades Centrales a tal efecto (art. 27.4 R. 2019/1111).

16. Se mantienen, por otro lado, algunas medidas como la audiencia del progenitor que solicita el retorno del menor (art. 27.1 R. 2019/1111) o las disposiciones relativas al mecanismo de prevalencia, que permite revocar un inicial pronunciamiento denegatorio del retorno del menor con una resolución posterior en materia de custodia que, dictada por las autoridades del Estado de origen, implique la devolución del menor al Estado de su residencia habitual (art. 29 R. 2019/1111).

17. Dicho todo lo anterior, hay que advertir que la relación va más allá de lo puramente procedimental, e incide sobre otras cuestiones de Derecho Internacional Privado. En concreto, se mantiene la regla especial de competencia judicial internacional que preserva para los jueces y tribunales del Estado Miembro de origen el conocimiento de las cuestiones de responsabilidad parental en caso de sustracción ilícita (art. 9 R. 2019/1111) ${ }^{16}$, y que se corresponde, a contrario sensu, con la prohibición de que los órganos jurisdiccionales del Estado de retención resuelvan sobre el fondo del asunto, prevista en el art. $16 \mathrm{CH}$ 80. Además, como novedad, se permite extender las reglas de la prorrogatio fori del art. $10 \mathrm{R}$. 2019/1111 también a los casos de sustracción internacional de menores, lo que, junto con la mediación, refuerza la apuesta por una solución pacífica de los conflictos dentro del propio ámbito familiar.

18. La mención al Capítulo IV suple el silencio del $\mathrm{CH} 80$ respecto a la eficacia transfronteriza de las resoluciones dictadas en los procesos de restitución. Finalmente, y como se establece en el art. 22 R. 2019/1111, también será de aplicación el Capítulo VI, que recoge "Disposiciones Generales" para las solicitudes que se emitan en aplicación del Reglamento, incluidas entre ellas, las de restitución de menores (art. 85 R. 2019/1111). Entre las cuestiones que regula este Capítulo VI, destaca como novedad la posibilidad de cooperación y comunicación directas entre órganos jurisdiccionales, extensible a las medidas provisionales, incluidas las cautelares, del art. 15 y al Capítulo III sobre el procedimiento de restitución (Art. 86 R. 2019/1111, en especial apartado 2, subapartados b) y d)).

19. Todas estas relaciones se explican en varios Considerandos. En concreto, el Considerando 16 R. 2019/1111 se refiere a la relación con las normas de competencia judicial internacional y de reconocimiento y ejecución, y en especial, a la aplicación del Capítulo IV a las resoluciones de restitución de menores como alternativa a otro proceso de restitución "como consecuencia de una nueva sustracción ocurrida tras haberse ordenado la restitución, sin perjuicio de la posibilidad de incoar un nuevo procedimiento de restitución de un menor en virtud del Convenio de La Haya de 1980". El Considerando 40 R. 2019/1111 indica que "en caso de traslado o retención ilícitos de un menor, es importante que su restitución se produzca sin demora, y con tal fin debe seguir aplicándose el Convenio de La Haya

${ }^{16}$ Esta regla ya se preveía anteriormente en el art. 10 R. 2201/2003. 
de 1980, completado por el presente Reglamento, en particular el Capitulo III'. Y el Considerando 73 R. 2019/1111, excluye la aplicación del Capítulo V, sobre cooperación de Autoridades en materia de responsabilidad parental, al mismo tiempo que reitera la interacción entre el $\mathrm{CH} 80$ con el régimen de sustracción internacional de menores del Reglamento, de reconocimiento y ejecución, y con el Capítulo VI, sobre disposiciones generales.

\section{Contextualización normativa del objeto de estudio: el régimen de medidas provisionales, inclui- das las cautelares en los procedimientos de restitución de menores.}

20. Como ya hemos tenido oportunidad de señalar, son muy numerosos los considerandos y artículos que, de una forma u otra, se refieren a la sustracción internacional de menores en el R. 2019/1111. Nuestro objetivo no es abarcar todos ellos, sino centrarnos en las reformas acaecidas en relación con las medidas provisionales, incluidas las cautelares. Por eso, antes de abordar su estudio, debemos concretar qué preceptos han de conformar nuestro análisis.

21. Por una parte, poco nos explica el CH 80 sobre este tipo de medidas. Su artículo 7.b) contempla el deber de las Autoridades Centrales de adoptar o hacer que se adopten medidas provisionales, para prevenir que el menor sufra mayores daños o que resulten perjudicadas las partes interesadas. Más allá de esta previsión, la atención de la Conferencia de La Haya de Derecho Internacional Privado se ha centrado en recomendar a los Estados Parte que establezcan líneas de acción en orden a evitar que la sustracción del menor llegue a producirse, y para ello ha elaborado una Guía de Buenas Prácticas sobre Medidas Preventivas, que recoge algunas directrices de soft law a tal efecto ${ }^{17}$. Pero dejando a un lado el enfoque preventivo, que será analizado en un epígrafe posterior ${ }^{18}$, es importante establecer un régimen concreto sobre medidas provisionales y cautelares una vez se produce el traslado o retención ilícitos, porque la trágica realidad es que se producen, por mucho que quieran prevenirse.

22. Frente al escaso pronunciamiento del Convenio, sí contamos en el nuevo Reglamento con un régimen más concreto. Como cuestión procedimental que es, nos circunscribimos en principio al Capítulo III R. 2019/1111. En él, existen dos preceptos que se refieren a la adopción de medidas provisionales, incluidas las cautelares, en caso de producirse una sustracción ilícita. En primer lugar, el apartado segundo del art. 27 R. 2019/1111 hace referencia a la posibilidad de garantizar durante el procedimiento de restitución el contacto entre el menor y la persona que solicita la restitución. Y en segundo lugar, el apartado quinto del mencionado artículo regula la adopción de estas medidas una vez se decide que el menor ha de ser devuelto "a fin de proteger al menor del riesgo mencionado en el artículo 13, párrafo primero, letra b), del Convenio de La Haya de 1980, siempre que el estudio y la adopción de dichas medidas no retrase indebidamente el procedimiento de restitución".

23. Ambos apartados se refieren al art. 15 R. 2019/1111, un precepto que se encuentra en la Sección Segunda del Capítulo II del nuevo Reglamento, que recoge las normas de competencia judicial internacional en materia de responsabilidad parental. Ello quiere decir que las medidas provisionales, incluidas las cautelares, deben ser estudiadas también desde la óptica de la competencia judicial internacional, y tendremos que tomar aquel precepto a modo de punto de partida de nuestro análisis, dado que sus innovaciones serán aplicables, por remisión, a las medidas dictadas en los procedimientos de restitución de menores. Dicho art. 15 R. 2019/1111 incorpora, además, previsiones acerca de la comunicación entre órganos jurisdiccionales, directamente o a través de las Autoridades Centrales, que serán igualmente comentadas.

\footnotetext{
17 Conferencia de La Haya de Derecho Internacional Privado. "Guía de buenas prácticas en virtud del Convenio de La Haya del 25 de octubre de 1980 sobre los aspectos civiles de la sustracción internacional de menores - Tercera Parte - Medidas de prevención", recuperado de: https://assets.hcch.net/docs/04e14dc3-14a7-4d40-965b-1655124489b0.pdf.

${ }^{18} \mathrm{Vid}$. infra, Epígrafe IV.
} 
24. Del mismo modo, hay que percatarse de que una de las novedades del R. 2019/1111 es la extensión del régimen jurídico de reconocimiento y ejecución de resoluciones no solamente a las decisiones sobre restitución del menor, sino también a las medidas provisionales y cautelares que la acompañen (art. 2.1.b) R. 2019/1111), lo que nos conecta con las especificidades que, sobre la eficacia extraterritorial de las medidas provisionales y cautelares, contengan las normas del Capítulo IV.

25. En definitiva, nos encontramos ante un régimen que, pese a ser muy específico, se caracteriza por su transversalidad en el Reglamento. Esto implica que, si bien nuestra atención se centrará en los apartados segundo y quinto del art. 27 R. 2019/1111, inevitablemente, habremos de conectar su análisis con cuestiones de competencia judicial internacional, reconocimiento y ejecución de resoluciones, y de cooperación entre autoridades centrales y judiciales.

26. Todo ello será expuesto en los siguientes epígrafes, sin olvidar que tenemos la atención puesta en el ordenamiento jurídico español, y en especial, en el régimen jurídico que la Ley de Enjuiciamiento Civil $^{19}$ (en adelante, LEC) contiene en los arts. 778 quáter a sexies sobre los procedimientos de restitución de menores en supuestos de sustracción internacional, incorporado en el año $2015^{20}$. En ese mismo año, la Fiscalía General del Estado publicó su Circular 6/2015, sobre Aspectos Civiles de la Sustracción Internacional de Menores, que aclara muchos aspectos sobre los procesos de restitución en España ${ }^{21}$.

\section{La reforma del R. 2019/1111 en relación al régimen general de adopción de medidas provisio- nales, incluidas las cautelares: el artículo 15 R. 2019/1111}

\section{Los requisitos para su adopción en defecto de competencia sobre el fondo del asunto}

27. Como veníamos indicando, un aspecto especialmente relevante de la reforma se produce en torno al papel de las medidas provisionales y cautelares del art. 15 R. 2019/1111, el cual comparte ciertos rasgos comunes con el art. 20 R. 2201/2003, si bien incorpora algunos matices que ha ido esclareciendo la jurisprudencia del TJUE.

28. La competencia para dictar medidas provisionales, incluidas las cautelares, puede corresponder al órgano jurisdiccional que conozca del fondo del asunto, que será determinado por las normas de competencia judicial internacional sin mayor problema. Pero también puede dictar dichas medidas un órgano jurisdiccional distinto del materialmente competente de forma excepcional y condicionada a una serie de requisitos ${ }^{22}$ que deben concurrir acumulativamente, según la STJCE de 2 de abril de 2009, asunto C-523/07, $A^{23}$.

29. En primer lugar, se requiere la urgencia en la necesidad de su adopción ${ }^{24}$. Según el TJUE, tal exigencia debe valorarse según la situación del menor, su evolución, la eficacia o la imposibilidad

\footnotetext{
${ }^{19}$ Ley 1/2000, de 7 de enero, de Enjuiciamiento Civil, BOE núm. 7, de 8 de enero de 2000.

${ }^{20}$ El procedimiento de restitución de menores en supuestos de sustracción internacional fue incorporado a la LEC en virtud de la Disposición final tercera, apartados 11 a 13, de la Ley 15/2015, de 2 de julio, de la Jurisdicción Voluntaria, BOE núm. 158, de 3 de julio de 2015.

${ }^{21}$ El texto completo de la Circular puede consultarse a través del siguiente enlace: https://www.fiscal.es/documents/ 20142/79c1a677-8c8f-bd7f-304a-0afac6aeeb25.

${ }^{22} \mathrm{Al}$ respecto vid. I. Pretelli. "Provisional Measures in Family Law and the Brussels II ter Regulation", Yearbook of Private International Law, Volume 20 (2018/2019), pp. 128-129; A. Bernardo SAN José. "Las normas de competencia internacional en materia de responsabilidad parental en el Reglamento (UE) 2019/1111 del Consejo de 25 de junio de 2019", Cuadernos de Derecho Transnacional (octubre 2020), Vol. 12, Núm. 2, p. 1283.

${ }^{23}$ ECLI:EU:C:2009:225, pár. 47.

${ }^{24}$ I. Pretelli. "Provisional Measures in Family Law and the Brussels II ter Regulation", op. cit., pp. 132-134; U. MagnUs, y P. Mankowski. European commentaries on Private International Law. Brussels II bis Regulation. Otto Schmidt, Köln, 2017, p. 278.
} 
de accionar ante el tribunal competente sobre el fondo del asunto ${ }^{25}$. Además, y ligado a la sustracción internacional de menores, el TJUE ha negado que la integración del menor en un nuevo entorno, originada por un traslado ilícito, cumpla con el requisito de urgencia, de modo que permita modificar una resolución provisional del tribunal competente sobre la custodia mediante una medida cautelar dictada por las autoridades del Estado Miembro de retención del menor ${ }^{26}$.

30. Dichas aclaraciones sobre cómo ha de valorarse la situación de urgencia no se han incorporado en el art. 15 R. 2019/1111, ni tampoco en sus Considerandos. En los procedimientos de restitución, la urgencia se relacionaría con el grave riesgo de un peligro físico o psíquico para el menor, ya que el art. 27.5 R. 2019/1111 permite, en caso de devolución del menor, la adopción de medidas para evitar que el menor se exponga a ese riesgo. El Considerando 76 R. 2019/1111 también sugiere esta relación cuando ejemplifica, como situación de urgencia, "una solicitud directa a la autoridad competente de otro Estado miembro para que examine la necesidad de adoptar medidas para la protección del menor cuando se considere que está en riesgo inminente". Por su parte, el Considerando 79 R. 2019/1111 alude al deber de las Autoridades Centrales de garantizar la cooperación y comunicación directas entre los órganos jurisdiccionales "en particular para la aplicación de (...) las normas sobre medidas provisionales, incluidas las cautelares en casos de urgencia, concretamente en relación con la sustracción internacional de menores y con objeto de proteger al menor del grave riesgo a que se refiere el artículo 13, párrafo primero, letra b), del Convenio de La Haya de 1980.

31. La segunda característica es la presencia del menor y/o sus bienes en el Estado miembro donde se va a adoptar la medida. Retomando la STJCE de 2 de abril de 2009, asunto C-523/07, $A$, esa presencia no ha de corresponderse necesariamente con la residencia habitual, sino con la coincidencia espacial en el mismo Estado Miembro entre el sujeto y el peligro que justifica la necesidad de adoptar la medida ${ }^{27}$. El nuevo Reglamento ha cambiado, respecto al anterior, la genérica denominación de "personas" por la de "menor", lo cual soluciona, en opinión de E. RodRíGuez PINEAU ${ }^{28}$, el criticado razonamiento del TJUE que consideraba, respecto de una medida de custodia provisional, que tanto el menor como sus progenitores debían estar presentes en el Estado Miembro donde esa medida fuera a dictarse ${ }^{29}$.

32. La tercera y última característica es la provisionalidad de la medida. El carácter provisional no se traduce en una duración temporal concreta, sino que de la letra del art. 15 R. 2019/1111 se deduce, como de su antecesor, que el límite máximo de perdurabilidad se corresponde con el momento en que

${ }^{25}$ STJCE de 2 de abril de 2009, asunto C-523/07, A, (ECLI:EU:C:2009:225), pár. 60; STJUE de 23 de diciembre de 2009, asunto C-403/09 PPU, Detiček (ECLI:EU:C:2009:810), pár. 42 y STJUE de 15 de julio de 2010, asunto C-256/09, Purrucker (ECLI:EU:C:2010:437), pár. 94. Según A. Bernardo SAn José. "Las normas de competencia internacional en materia de responsabilidad parental en el Reglamento (UE) 2019/1111 del Consejo de 25 de junio de 2019”, op. cit., p. 1284, bajo la interpretación de urgencia dada por el TJUE, sólo caben medidas cautelares con carácter previo a la interposición de la demanda. Cabe discrepar de esta afirmación toda vez que el artículo 27.2 R. 2019/1111 permite adoptar, conforme al art. 15, medidas provisionales de contacto con el menor "en cualquier fase del procedimiento" que decide sobre la restitución del menor, e igualmente, conforme al art. 27.5 R. 2019/1111, se permitiría dictar medidas una vez se ha decidido devolver al menor, es decir, una vez dictada la resolución judicial.

${ }^{26}$ STJUE de 23 de diciembre de 2009, asunto C-403/09 PPU, Detiček (ECLI:EU:C:2009:810), pár. 47-49.

${ }^{27}$ Como se indica en la STJCE de 2 de abril de 2009, asunto C-523/07, A, (ECLI:EU:C:2009:225), pár. 48: "Dichas medidas son aplicables a los menores que teniendo su residencia habitual en un Estado miembro residen con carácter temporal u ocasional en otro Estado miembro y se encuentran en una situación que puede perjudicar gravemente a su bienestar, incluida su salud, o su desarrollo, por lo que está justificada la adopción inmediata de medidas de protección...", en el mismo sentido, vid. Conclusiones de la Abogado General, Sra. Juliane Kоккот, presentadas el 29 de enero de 2009, asunto C-523/07, A, ECLI:EU:C:2009:39, pár. 57.

${ }^{28}$ Vid. E. Rodríguez Pineau, "La refundición del Reglamento Bruselas II bis: De nuevo sobre la función del Derecho Internacional Privado Europeo", REDI, vol. 69/1, enero-junio 2017, p. 162.

${ }^{29}$ STJUE de 23 de diciembre de 2009, asunto C-403/09 PPU, Detiček (ECLI:EU:C:2009:810), pár. 50-52. Entre las voces críticas, vid. P. JimÉnez Blanco. "Medidas cautelares y sustracciones de menores", Diario La Ley, Núm. 7601, Sección Tribuna, 31 de marzo de 2011, Año XXXII, p. 8, y T. KrUger y L. SAmyn. "Brussels II bis: successes and suggested improvements", Journal of Private International Law, 2016, pp. 148-149. 
el órgano competente sobre el fondo se pronuncie, estableciendo las medidas que estime pertinentes. Como apuntaba la Abogada General, Sra. Juliane Коккот, en sus Conclusiones al asunto C-523/07: “... Si el órgano jurisdiccional que adoptó la medida provisional no impuso ningún plazo de duración ni derogó la misma, la medida seguirá vigente hasta que intervenga el órgano jurisdiccional competente para conocer del fondo del asunto, según el artículo 20, apartado 2 del Reglamento" 30 (referencia que deberemos entender hecha al nuevo apartado 15.2 R. 2019/1111 a partir del 1 de agosto de 2022).

33. Existía cierto debate doctrinal acerca de si el contenido de las medidas provisionales y cautelares debe comprenderse dentro del ámbito material del Reglamento o no. El art. 15 R. 2019/1111 no recoge expresamente una respuesta a esta cuestión, sólo se remite al Derecho de cada Estado miembro para concretarlas ${ }^{31}$. Muchos autores, reflexionando sobre los instrumentos europeos precedentes, han sostenido que $i^{32}$, entre otras razones, dado que algunas materias matrimoniales o parentales excluidas del antiguo R. 2201/2003, cuentan con su propio Reglamento, al que podrá acudirse para esta cuestión ${ }^{33}$. En el nuevo Reglamento, la extensión de las medidas provisionales, incluidas las cautelares, a la cuestión de las sustracciones internacionales de menores es pacífica, como evidencia la remisión al art. 15 de los apartados 2 y 5 del art. 27 R. 2019/1111 con ocasión de los procedimientos de restitución. Apoya esta idea la mencionada extensión de la noción de "materia civil" que enuncia el Considerando $5 \mathrm{R}$. 2019/1111 a los actos procesales relativos al procedimiento de restitución de menores ${ }^{34}$.

34. Consecuentemente, la competencia de la autoridad que dicte la medida debe abarcar dichas materias del art. 1 R. 2019/1111 ${ }^{35}$. El TJUE ha entendido comprendidas en el ámbito del R. 2201/2003 las medidas civiles dictadas por autoridades administrativas en régimen de Derecho Público ${ }^{36}$. Además,

${ }^{30}$ Conclusiones de la Abogado General, Sra. Juliane Kоккот, op. cit., pár. 60; STJCE de 2 de abril de 2009, asunto C-523/07, A, (ECLI:EU:C:2009:225), pár. 48.

${ }^{31}$ Remisión confirmada por la jurisprudencia, Vid. STJCE de 2 de abril de 2009, C-523/07, A (ECLI:EU:C:2009:225), pár. 65.

${ }^{32}$ Así lo indican U. Magnus, Y P. MANKowsKi. European commentaries on Private International Law. Brussels II bis Regulation, op. cit., 2017, pp. 274-275, M. Župan, S. Ledić y M. Drventić. "Provisional Measures and Child Abduction Proceedings", Pravni Vjesnik, God. 35 Br. 1, 2019, p. 14. La tesis de la circunscripción de las medidas cautelares al ámbito de aplicación de los Reglamentos 1347/2000 y 2201/2003 también es apoyada por H. SolETo. Las medidas provisionales en los procesos de familia, Tirant Lo Blanch, Valencia, 2002, pp. 216-217; R. Arenas García. Crisis Matrimoniales Internacionales. Nulidad matrimonial, separación y divorcio en el nuevo Derecho internacional privado español, Servicio de Publicacións da Universidade de Santiago de Compostela, 2004, pp. 175-177. No obstante, podemos encontrar una opinión contraria por parte de F.-J. ForCADA MiRANDA. Comentarios prácticos al Reglamento (UE) 2019/1111. Competencia, Reconocimiento y Ejecución de Resoluciones en materia Matrimonial, Responsabilidad Parental y Sustracción Internacional de Menores, Sepin, Madrid, 2020, pp. 150-151.

${ }^{33}$ Por ejemplo, para los alimentos, se acudiría a los arts. 18 y 36 del Reglamento (CE) 4/2009 del Consejo, de 18 de diciembre de 2008, relativo a la competencia, la ley aplicable, el reconocimiento y la ejecución de las resoluciones y la cooperación en materia de obligaciones de alimentos (DOUE, L 7, de 10 de enero de 2009); en materia de régimen económico matrimonial, también regula esta cuestión el art. 19 del Reglamento (UE) 2016/1103 del Consejo, de 24 de junio de 2016, por el que se establece una cooperación reforzada en el ámbito de la competencia, la ley aplicable, el reconocimiento y la ejecución de resoluciones en materia de regímenes económicos matrimoniales (DOUE, L 183, de 8 de julio de 2016). En cuestiones sucesorias que pudieran atener al menor, habríamos de remitirnos al art. 19 del Reglamento (UE) núm. 650/2012 del Parlamento Europeo y del Consejo, de 4 de julio de 2012, relativo a la competencia, la ley aplicable, el reconocimiento y la ejecución de las resoluciones, a la aceptación y la ejecución de los documentos públicos en materia de sucesiones mortis causa y a la creación de un certificado sucesorio europeo (DOUE L 201, de 27 de julio de 2012). Igualmente, contamos con el Reglamento (UE) núm. 606/2013 del Parlamento Europeo y del Consejo, de 12 de junio de 2013, relativo al reconocimiento mutuo de medidas de protección en materia civil (DOUE L 181, de 29 de junio de 2013), que regula la eficacia extrafronteriza de las medidas protectoras no comprendidas en el ámbito de aplicación del R. 2201/2003, como indica su art. 1.3.

${ }^{34}$ El Considerando 5 R. 2019/1111 afirma: "El presente Reglamento se aplica en «materia civil», (...) la noción de «materia civil» debe abarcar las demandas, medidas o resoluciones, así como los documentos públicos y determinados acuerdos extrajudiciales referentes a la restitución de un menor en virtud del Convenio de La Haya de 1980, que, según la jurisprudencia del Tribunal de Justicia y conforme al artículo 19 del Convenio de La Haya de 1980, no sean procedimientos sobre el fondo acerca de la responsabilidad parental, pero estén estrechamente relacionadas con esa cuestión y sean objeto de determinadas disposiciones del presente Reglamento".

${ }^{35}$ Vid. Dirección General de Justicia (Comisión Europea). "Guía práctica para la aplicación del Reglamento Bruselas II bis", recuperado de: https://op.europa.eu/es/publication-detail/-/publication/f7d39509-3f10-4ae2-b993-53ac6b9f93ed, p. 23.

${ }^{36}$ Como muestra la STJCE de 2 de abril de 2009, asunto C-523/07, A (ECLI:EU:C:2009:225), pár. 28-29, donde se puso de manifiesto que una medida de guarda y acogimiento de menores dictada por una autoridad finlandesa conforme al Derecho 
nuestra jurisprudencia menor también ha indicado que la competencia para dictar medidas cautelares al amparo del R. 2019/1111 se ciñe a la jurisdicción civil, y no a la penal ${ }^{37}$.

35. Nuestra legislación nacional es consecuente con los requisitos para las medidas provisionales, incluidas las cautelares, anteriormente analizados. El condicionante de la urgencia es compartido por nuestra legislación española, que exige justificar el denominado "periculum in mora" (728.1 LEC) ${ }^{38}$, esto es, el riesgo que comporta no adoptar la medida de forma urgente. Si tomamos por base el procedimiento de restitución del menor, la LEC es bastante flexible sobre el momento de adoptar la medida cautelar (art. 778 quáter. 8 LEC, párrafo primero), lo que ampara la idea de que la urgencia pueda resultar sobrevenida: la LEC se fija, sobre todo, en el supuesto de incomparecencia del menor por rebeldía del sustractor (art. 778. quinquies. 5 LEC, párrafo segundo) ${ }^{39}$.

36. También son requisitos generales para la adopción de medidas cautelares en nuestra legislación la apariencia de buen derecho (art. 728.2 LEC) y la prestación de caución (art. 728.3 LEC). Siguiendo a M. LÓPEZ JARA, la apariencia de buen derecho se satisfaría por el progenitor demandante dando indicios de la residencia habitual del menor en el Estado de origen y de su facultad de decidir sobre aquélla ${ }^{40}$. La jurisprudencia europea ha proporcionado valiosas aclaraciones sobre elementos indiciarios denotativos de la residencia habitual del menor $^{41}$, bien acogidas por la jurisprudencia española, que toma, entre otros criterios aclaratorios, elementos como la escolarización del menor en el Estado Miembro, su inscripción en el sistema sanitario o la relación laboral del progenitor en el Estado Miembro. En lo que respecta a la capacidad para decidir sobre la residencia del menor, basta que el progenitor demuestre la titularidad jurídica de su custodia para que, apriorísticamente, se presuma su ejercicio efectivo hasta el momento del traslado o retención ilícitos, y con ello, necesariamente, se demuestra su capacidad para determinar dónde vive el menor $^{42}$. El requisito de la caución queda dispensado, de

Público se encuentra comprendida entre las materias civiles contempladas en el Reglamento. Vid. I. Pretelli. "Provisional Measures in Family Law and the Brussels II ter Regulation", op. cit. p. 136.

${ }^{37}$ Nos referimos al AAP Granada (Sección 2a ${ }^{\mathrm{a}}$ ) núm. 513/2019, de 12 de agosto (ECLI:ES:APGR:2019:1092A), un pronunciamiento llamativo porque razona sobre el R. 2019/1111 sin hacer referencia al R. 2201/2003, que es el que, a fecha de la resolución, todavía se aplica. En su fundamento jurídico segundo, puede leerse: “...la prevención que el Reglamento hace en su artículo 15 estableciendo en los casos de urgencia la competencia de los órganos jurisdiccionales de un Estado miembro para adoptar medidas provisionales y cautelares sobre menores presentes en su territorio, aunque no la tengan para conocer del fondo del asunto por corresponderle a un órgano jurisdiccional de otro Estado miembro, con posterior remisión de la Causa a la Jurisdicción del Estado competente, ha de entenderse referida a la Jurisdicción Civil, no a la Penal como erróneamente interpreta el recurso".

${ }^{38} \mathrm{Al}$ respecto vid. S. CALAza López. Los procesos de restitución o retorno de menores en los supuestos de sustracción internacional, Wolters Kluwer, Madrid, 2015, pág. 89, que, al mencionar el requisito de la urgencia, añade seguidamente, entre paréntesis, la expresión latina "periculum im mora". En el mismo sentido, vid. I. PretelLi. "Provisional Measures in Family Law and the Brussels II ter Regulation", op. cit., p. 133, que relaciona "urgencia" con el requisito de "periculum in mora" presente en el art. 8 del Convenio sobre competencia de las Autoridades y la Ley aplicable en materia de protección de menores, hecho en La Haya el 5 de octubre de 1961 (BOE núm. 199 de 20 de agosto de 1987), así como con el grave riesgo de daño para el menor.

${ }^{39}$ Como afirma la Fiscalía General del Estado en su Circular 6/2015, pág. 70: "El inciso segundo del apartado quinto del art. 778 quinquies de nuevo prevé la posibilidad de adoptar medidas cautelares cuando al primer llamamiento el demandado no comparece o no lo hace en forma, no presentando al menor. Es claro que en estos casos el comportamiento procesal del demandado pone de manifiesto un incremento en el periculum in mora, por lo que será especialmente aconsejable la adopción, si no se hubiera hecho ya, de medidas cautelares."

${ }^{40} \mathrm{Vid}$. M. López JARA. "El proceso cautelar en materia de sustracción internacional de menores", La Ley Derecho de familia: Revista jurídica sobre familia y menores, Núm. 10, Segundo trimestre de 2016, p. 6.

${ }^{41}$ Para un estudio completo sobre el foro de la residencia habitual y sus criterios, vid. J. CARrascosa GonzÁlez. "Litigación Internacional, responsabilidad parental y foro de la residencia habitual del menor en un Estado Miembro. Un estudio jurisprudencial", en A. Cebrian Salvat e I. Lorente Martínez (dirs.). Protección de Menores y Derecho Internacional Privado. Comares, Granada, 2019, pp. 307-323.

${ }^{42}$ Como indica la SAP León (Sección 2a ) núm. 117/2020, de 12 de mayo (ECLI:ES:APLE:2020:544), al titular se le exige simplemente "una primera evidencia de que ejercía realmente el cuidado sobre la persona del menor, si bien del conjunto del Convenio (arts. 3,8,13) se deduce que está basado en la presunción de que la persona que está al cuidado del menor ejerce efectivamente su custodia, recayendo sobre el "secuestrador" la carga de probar que no es asi". En el mismo sentido, E. 
acuerdo con M. LÓPEZ JARA, por efecto del art. $22 \mathrm{CH} 80$, que dispone expresamente: "No podrá exigirse fianza ni depósito alguno, cualquiera que sea la denominación que se le dé, para garantizar el pago de las costas y gastos de los procedimientos judiciales o administrativos previstos en el Convenio" 43 .

37. En cuanto a la presencia en el Estado Miembro, a efectos nacionales, las medidas cautelares en los procesos de restitución, se dictan sobre la base de que el menor se encuentra presente en el Estado español (art. 778 quáter. 1 LEC).

38. La provisionalidad también se contempla como una característica esencial de estas medidas: desde el régimen general, el art. 726.2 LEC se refiere expresamente a ello y, además, siendo más específico que la norma europea, pues se permite que, durante el procedimiento, se puedan modificar, modular o incluso dejar sin efecto las medidas cautelares (art. 743 LEC). Es decir, nuestra legislación nacional permite suspender una medida cautelar bajo la mera evidencia de la desaparición del riesgo que la motiva, sin necesidad de esperar a que el órgano competente sobre el derecho de custodia dicte alguna medida.

\section{La comunicación entre órganos jurisdiccionales y Autoridades Centrales}

39. El art. 15 R. 2019/1111, establece un deber de comunicación bilateral entre el órgano jurisdiccional excepcionalmente competente para dictar medidas provisionales, incluidas las cautelares, y el competente sobre el fondo del asunto, bien directamente, bien a través de las Autoridades Centrales, si el interés superior del menor lo exige ${ }^{44}$.

40. Se trata de la recepción en el nuevo Reglamento de la doctrina jurisprudencial recogida en la ya citada STJCE de 2 de abril de 2009, asunto C-523/07, $A^{45}$. En el conflicto de origen, se discutía que las autoridades finlandesas fuesen competentes para adoptar una medida de guarda e internamiento en un establecimiento de acogida de unos menores suecos que, de forma itinerante, se instalaban en diversos campings de Finlandia por vacaciones sin estar escolarizados. El TJUE estaba llamado a pronunciarse, entre otras cuestiones, sobre el deber de las autoridades finlandesas de trasladar los autos de oficio a los órganos jurisdiccionales suecos una vez adoptadas las medidas cautelares, lo cual niega. Pero seguidamente, en forma de obiter dictum, declara que, si el interés superior del menor lo exige, se ha informar de ellas al órgano jurisdiccional competente sobre el fondo del asunto, bien de forma directa, como expresión del art. 55.c) R. 2201/2003, o bien por medio de las Autoridades Centrales designadas conforme al art. 53 R. 2201/2003, y ello porque las circunstancias del menor "pueden hacer necesaria la intervención temprana del órgano jurisdiccional competente para que se adopten medidas definitivas".

41. La cooperación judicial directa no plantea especiales problemas en caso de medidas provisionales, incluidas las cautelares, dictadas ante una sustracción internacional de menores. Sin embargo, encontramos algo más problemática la articulación de la cooperación entre Autoridades cuando han de coligarse la colaboración a la hora de informar sobre dichas medidas con la cooperación en materia de sustracción internacional de menores.

\footnotetext{
Pérez-Vera. "Informe explicativo del Convenio sobre los Aspectos Civiles de la Sustracción Internacional de Menores". Disponible en español a través del siguiente enlace: https://assets.Conferencia de La Haya de Derecho Internacional Privado.net/ docs/43df3dd9-a2d5-406f-8fdc-80bc423cdd79.pdf, pp. 21-22, pár. 73.

${ }^{43} \mathrm{Vid}$. M. LÓPEZ JARA. "El proceso cautelar en materia de sustracción internacional de menores", op. cit. p. 7

${ }^{44}$ Esa exigencia dependerá de la valoración del órgano jurisdiccional que dicta la medida, según E. RoDríGUEz PINEAU, "La refundición del Reglamento Bruselas II bis: De nuevo sobre la función del Derecho Internacional Privado Europeo”, op. cit. p. 162.

${ }^{45}$ Vid. STJCE de 2 de abril de 2009, C-523/07, A (ECLI:EU:C:2009:225), pár. 56-65; E. Rodríguez Pineau. "El nuevo Reglamento (UE) 2019/1111 en materia matrimonial, responsabilidad parental y sustracción internacional de menores" La Ley Derecho de familia: Revista jurídica sobre familia y menores, Núm. 26, Segundo trimestre de 2020, p. 7.
} 
42. Tengamos en cuenta que las medidas provisionales, incluidas las cautelares, previsiblemente incidirán sobre cuestiones de responsabilidad parental (guarda o custodia provisional, acogimiento, régimen de visitas...). Para informar de estas medidas, el art. 15.2 R. 2019/1111 se remite al art. 76 R. 2019/1111, donde se prevé la designación de una Autoridad Central por cada Estado Miembro para "asistirlo en la aplicación del presente Reglamento con respecto a las cuestiones de responsabilidad parental". Esa cooperación abarcaría entonces todas aquellas medidas provisionales, incluidas las cautelares, que se dictasen en caso de sustracción internacional de menores y que pudieran tener incidencia sobre la cuestión de responsabilidad parental. Sin embargo, la cooperación no alcanza a los procedimientos de restitución de menores en sí mismos, ya que el Considerando 73 los excluye del ámbito de aplicación del Capítulo V del R. 2019/1111 ${ }^{46}$. Esto tiene dos consecuencias que resultan incoherentes. Por un lado, en los Estados Miembros que tienen designada una misma Autoridad Central para ambos ámbitos de cooperación ${ }^{47}$, la cooperación se regirá por el escueto régimen $\mathrm{CH} 80^{48}$ para la restitución y por el más desarrollado del R. 2019/1111 para las medidas provisionales, incluidas las cautelares; sin posibilidad de complementar ambos instrumentos. Por otro lado, para aquellos Estados Miembros que tienen designada una Autoridad Central distinta según el ámbito de cooperación ${ }^{49}$, a la dualidad normativa se le une la dualidad institucional, lo cual puede ser causa de dificultades.

43. La comunicación, bien mediante Autoridades Centrales o a través de órganos jurisdiccionales, se regula también para informar desde el Estado Miembro de origen de que se han adoptado las medidas para evitar el grave riesgo y así evitar que se aplique la causa de denegación del retorno del art. 13, párrafo primero, b) $\mathrm{CH} 80$ (art. 27.4 R. 2019/1111). Para ello el órgano jurisdiccional, una vez se haya dirigido a las partes, podrá solicitar el auxilio de las Autoridades Centrales, de la Red Judicial Europea en materia civil y mercantil, o de la Red de Jueces de La Haya (Considerando 45 R. 2019/1111). En todo caso, la carga de la prueba sobre la adopción de las medidas para evitar el grave riesgo recae sobre el progenitor que solicita la restitución (art. 27.3 R. 2019/1111).

\section{La nueva ubicación del art. 15 R. 2019/1111 y su repercusión}

44. Como anticipábamos en el apartado dedicado a la contextualización normativa, el art. 15 R. 2019/1111 se encuentra ahora situado en la Sección Segunda del Capítulo II del nuevo Reglamento.

\footnotetext{
${ }^{46}$ Como indica el Considerando 73 R. 2019/1111: “Las disposiciones del presente Reglamento sobre cooperación en materia de responsabilidad parental no deben aplicarse al trámite de solicitudes de restitución en virtud del Convenio de La Haya de 1980 que, de conformidad con el artículo 19 de dicho Convenio y la jurisprudencia reiterada del Tribunal de Justicia, no constituyen procedimientos sobre el fondo de la responsabilidad parental. Sin embargo, la aplicación del Convenio de La Haya de 1980 se debe complementar con las disposiciones del presente Reglamento en materia de sustracción internacional de menores y con el capitulo del presente Reglamento sobre reconocimiento y ejecución y el capitulo sobre las disposiciones generales".

${ }^{47}$ El R. 2019/1111 recomienda valerse de la misma Autoridad Central (Considerando 72). En España, dicha Autoridad común es la Subdirección General de Cooperación Jurídica Internacional, adscrita al Ministerio de Justicia. Vid. Real Decreto 453/2020, de 10 de marzo, por el que se desarrolla la estructura orgánica básica del Ministerio de Justicia, y se modifica el Reglamento del Servicio Jurídico del Estado, aprobado por el Real Decreto 997/2003, de 25 de julio. BOE núm. 63, de 12 de marzo de 2020, artículo 8.2.a)

${ }^{48} \mathrm{El}$ escaso desarrollo del régimen de las Autoridades Centrales se debe, de acuerdo con B. Gómez BengoecheA. Aspectos civiles de la sustracción internacional de menores. Problemas de aplicación del Convenio de La Haya de 1980, Colección "Monografías de Derecho Civil". Dykinson, Madrid, 2002, p. 47 al deseo de respetar las diferencias organizativas entre los Estados Parte del CH 80

${ }^{49}$ Por ejemplo, Lituania, que divide la competencia en materia de cooperación entre el Ministerio de Justicia -para responsabilidad parental-, el Servicio Estatal de Protección de los Derechos Civiles de los menores y de Adopción, adscrito al Ministerio de Trabajo y Seguridad Social -para sustracción internacional-; y Hungría, que hace lo mismo a través del Ministerio de Recursos Humanos - para cooperación en responsabilidad parental- y el Departamento de Derecho Internacional Privado del Ministerio de Justicia - para sustracción internacional. El resto de Estados Miembros se vale de la misma Autoridad Central para cooperar en los dos ámbitos. Puede consultarse el listado de Autoridades Centrales para los Estados Miembros en los siguientes enlaces: https://www.hcch.net/es/instruments/con ventions/authorities1/print1/?cid=24 (listado de Autoridades Centrales para la cooperación en la restitución de menores) y https://e-justice.europa.eu/content matrimonial_matters_and matters_of_parental_responsibility-377-es.do (listado de Autoridades Centrales para la cooperación en materia de responsabilidad parental).
} 
Una ubicación novedosa ya que, con anterioridad a la reforma, la regla sobre medidas cautelares formaba parte de la Sección Tercera, consagrada a un régimen de disposiciones comunes a las reglas de competencia judicial internacional. Desde esta nueva posición, el nuevo artículo 15 R. 2019/1111 se consagra como una norma de competencia judicial internacional en materia de responsabilidad paren$\mathrm{tal}^{50}$, que se reafirma además por la fuerza de sus palabras, al establecerse que: “...aunque el órgano jurisdiccional de otro Estado miembro sea competente para conocer del fondo del asunto, los órganos jurisdiccionales de un Estado miembro tendrán competencia para adoptar medidas provisionales, incluidas las cautelares..." ${ }^{51}$.

45. Estas modificaciones son herederas de la Propuesta de reforma planteada por la Comisión en $2016^{52}$, que planteó estas modificaciones persiguiendo unos objetivos más ambiciosos en cuanto a la repercusión de esta regla de competencia en la posibilidad de reconocimiento y ejecución de las medidas provisionales dictadas al amparo del artículo 12 de dicha Propuesta (referido a las medidas provisionales, incluidas las cautelares). Recurrimos, para explicarlo, a un breve sumario histórico-legislativo.

46. Todo parte del conflicto planteado en la STJUE de 15 de julio de 2010, C-256/09, Purruc$k e r^{53}$, que resuelve una cuestión prejudicial acerca de si las normas de reconocimiento y ejecución de resoluciones en materia de responsabilidad parental se aplican a las medidas provisionales, incluidas cautelares, dictadas $e x$ art. 20 R. 2201/2003. El Tribunal responde que no, debido a que el art. 20 no es una regla sobre competencia, sino una disposición general excepcional, condicionada por los requisitos de urgencia, presencia y provisionalidad. Esa excepcionalidad no desplazaba, sino que reafirmaba la competencia de aquellos órganos competentes para pronunciarse sobre el fondo, y que podían adoptar medidas que prevalecieran sobre las adoptadas por los órganos jurisdiccionales de otro Estado miembro al amparo del art. 20.

47. Cuando la Comisión presenta en 2016 la Propuesta de reforma del Reglamento 2201/2003, se observa una actitud rompedora con la doctrina expuesta, para extender la eficacia extraterritorial a todas las medidas provisionales y cautelares sin distinción. Así, el Considerando 17 de la Propuesta de Reglamento apelaba a que las medidas cautelares urgentes, provisionales y sobre bienes y personas presentes en el Estado miembro, dictadas por órganos no competentes sobre el fondo, fueran "reconocidas y ejecutadas en los demás Estados miembros, incluidos los Estados miembros que sean competentes en virtud del presente Reglamento", hasta su modificación o sustitución por parte de los órganos competentes para conocer del fondo del asunto. Reiteraba en parecidos términos el Considerando 40 de la Propuesta esta voluntad para hacer extensible las normas sobre reconocimiento y ejecución "a las medidas provisionales, incluidas las medidas cautelares, ordenadas en casos urgentes con arreglo al art. 12 del presente Reglamento por una autoridad de un Estado miembro que no sea competente en cuanto al fondo del asunto" 54 .

48. Esta es la razón por la que se reubicó el art. 20 del R. 2201/2003 -art. 12 en la Propuesta de la Comisión- en la Sección 2a del Capítulo II, sobre normas de competencia judicial internacional en materia de responsabilidad parenta ${ }^{55}$, desvirtuando el mencionado razonamiento del TJUE en el caso

\footnotetext{
${ }^{50} \mathrm{Vid}$. A. Bernardo SAn José. "Las normas de competencia internacional en materia de responsabilidad parental en el Reglamento (UE) 2019/1111 del Consejo de 25 de junio de 2019”, op. cit., p. 1283.

${ }^{51}$ Vid. E. Rodríguez Pineau. "El nuevo Reglamento (UE) 2019/1111 en materia matrimonial, responsabilidad parental y sustracción internacional de menores", op. cit., pp. 6-7.

${ }^{52}$ Vid. supra, nota 6.

${ }^{53}$ STJUE de 15 de julio de 2010, asunto C-256/09, Purrucker (ECLI:EU:C:2010:437), pár. 61, 76-78 y 87.

${ }^{54}$ Esa previsión sobre la eficacia extraterritorial se inspira en el CH 96, vid. Permanent Bureau of the Hague Conference on Private International Law. "The Link With International Instruments And Third Countries", en A.A.V.V., "Recasting the Brussels IIa Regulation, Workshop 8 November 2016", Compilation of briefings for the JURI Committee, 2016, recuperado de: https://www.europarl.europa.eu/RegData/etudes/STUD/2016/571383/IPOL_STU(2016)571383_EN.pdf, pp. 66 y 69-70.

${ }^{55}$ Así lo afirman P. Beaumont. L. Walker, y J. Holliday. "Parental Responsibility and International Hague Abduction in the proposal recast of Brussels IIa Regulation and the effect of Brexit on future child abduction proceedings", Working Pa-
} 
Purrucker, contrario a darle naturaleza de norma competencial ${ }^{56}$. Desde su nueva ubicación, el art. 12.1 de la Propuesta afirmaba que los órganos jurisdiccionales "tendrán competencia" en caso de urgencia para adoptar medidas cautelares sobre personas y bienes localizados en su Estado. Además, la Propuesta introdujo un art. 38, en la Sección $4^{\text {a }}$ del Capítulo IV sobre reconocimiento y ejecución, que declaraba: "Las disposiciones del presente capitulo aplicables a las resoluciones se aplicarán a las medidas provisionales, incluidas las cautelares, ordenadas por una autoridad competente de conformidad con el capitulo II'. Las normas de competencia del Capítulo II son las contenidas en las Sección $1^{\text {a }}$ sobre crisis matrimoniales, y en la Sección $2^{\mathrm{a}}$, a la cual se trasladó el art. 12 como una norma más de competencia sobre responsabilidad parental.

49. Sin embargo, poco de lo explicado hasta aquí se ha mantenido en el Reglamento 2019/1111. El art. 15 ha perdido, pese a mantenerse en la nueva ubicación y con los mismos términos de la Propuesta, la fuerza intencional que ésta le dio. La lectura del primer inciso del Considerando 30 del $\mathrm{R}$ 2019/1111 confirma la reconducción del precepto a una interpretación más concorde con la jurisprudencia del TJUE: "Dichas medidas [las del art. 15 R. 2019/1111] no deben ser reconocidas ni ejecutadas en ningún otro Estado miembro en virtud del presente Reglamento excepto las medidas adoptadas para proteger al menor de un grave riesgo a que hace referencia el artículo 13, párrafo primero, letra b), del Convenio de La Haya de 1980".

50. Pero, como puede observarse, sí se conserva la eficacia extraterritorial de las medidas cautelares destinadas a paliar el grave riesgo en caso de restitución del menor ${ }^{57}$. La forma de integrar dichas medidas en el ámbito de aplicación del Capítulo IV, destinado a las normas de reconocimiento y ejecución de resoluciones, se hace a partir de la definición de "resolución"s8.

51. Así el art. 2.1.b) R. 2019/1111 declara: “A los efectos del Capitulo IV, «resolución» incluye también: (...) b) medidas provisionales, incluidas las cautelares, ordenadas por un órgano jurisdiccional competente en virtud del presente Reglamento para conocer en cuanto al fondo del asunto o de las medidas ordenadas de conformidad con el artículo 27, apartado 5, en relación con el artículo 15. E1 art. 27.5 R. 2019/1111 se refiere a la posibilidad de dictar medidas cautelares en el caso de que se decida restituir al menor, para paliar el grave riesgo al que pudiera quedar sometido.

52. De igual modo, el Considerando 59 R. 2019/1111, indica que: “(...) Cuando las medidas provisionales, incluidas las cautelares, sean ordenadas por un órgano jurisdiccional de un Estado miembro que no es competente en cuanto al fondo del asunto, la circulación garantizada en virtud del presente Reglamento debe quedar circunscrita a las medidas ordenadas en casos de sustracción internacional de menores y destinadas a proteger al menor del grave riesgo a que se refiere el artículo 13, párrafo primero. letra b), del Convenio de La Haya de 1980 (...)".

per No. 2016/6, University of Aberdeen, School of Law. Recuperado de: https://www.abdn.ac.uk/law/documents/CPIL_Working_Paper_No_2016_6_revised.pdf, p. 10: “...the proposal moves this provision to the jurisdiction chapter which means any measures made under this provision can be recognised and enforced in another Member State". En el mismo sentido, vid. M. Župan, S. Ledić, y M. Drventić. "Provisional Measures and Child Abduction Proceedings", op. cit. p. 22.

${ }^{56} \mathrm{Vid}$. T. Kruger. "Enhancing Cross Border Cooperation", en A.A.V.V., "Recasting the Brussels IIa Regulation, Workshop 8 November 2016", op. cit. p. 38

${ }^{57}$ Vid. I. Pretelli. "Provisional Measures in Family Law and the Brussels II ter Regulation", op. cit., pp. 143-144, critica que este reduccionismo frente al carácter más ambicioso de la reforma se basa en una preservación de la competencia judicial internacional en detrimento del interés superior del menor.

${ }^{58}$ Vid. C. González Beilfuss. "La sustracción de menores en el nuevo Reglamento 2019/1111”, en A.A.V.V., Relaciones Transfronterizas, Globalización y Derecho. Homenaje al Profesor Doctor José Carlos Fernández Rozas. Editorial Aranzadi, Pamplona, 2020, pp. 390-391. 


\section{Las medidas provisionales, incluidas las cautelares, en el procedimiento de restitución de me- nores}

\section{Medidas durante el procedimiento: en especial, el contacto del menor con la persona que solicita su restitución (art. 27.2 R. 2019/1111)}

53. El art. 27.2 R. 2019/1111 expresa que "En cualquier fase del procedimiento, de conformidad con el art. 15, el órgano jurisdiccional podrá examinar si se debe garantizar el contacto entre el menor y la persona que solicita su restitución, teniendo en cuenta el interés superior del menor".

54. Una previsión nada extraña para nuestro ordenamiento jurídico, puesto que en términos parecidos (incluso más amplios) se expresa el art. 778 quáter.8 LEC, en su apartado segundo, que permite valorar la posibilidad de otorgar de forma provisional los derechos de estancia, visita, relación y comunicación con el menor.

55. El contacto entre el menor y el progenitor no tiene por qué ser la única medida provisional posible, pues, aunque el art. 27.2 sólo mencione esa medida, la referencia que se hace al art. 15 R. 2019/1111 entendemos que permitiría ir más allá. Las posibilidades adicionales podrían pasar por ejemplo por la custodia provisional, la guarda provisional por un tercero o el acogimiento institucional temporal del menor ${ }^{59}$, en caso de que el grave riesgo para el menor pudiera predicarse de la convivencia con ambos progenitores. Pensemos en la hipótesis de un menor retenido ilícitamente por un progenitor con graves problemas económicos que comprometen el sustento de su hijo, unido al grave riesgo de retornar al Estado de residencia habitual por el riesgo físico o psíquico que el otro progenitor le pudiera inferir a causa de violencia doméstica.

56. En todo caso, debe valorarse positivamente que se contemple expresamente la garantía del contacto con el progenitor que reclama la custodia durante el procedimiento de restitución, dentro de lo conveniente. Esta previsión legislativa es una manifestación del derecho de los progenitores a mantener el contacto con sus hijos, y a su vez, del derecho de las autoridades a garantizarlo de forma efectiva, como han expresado los convenios internacionales y la Jurisprudencia del TEDH ${ }^{60}$. Además, en tanto que operan los mecanismos contra la sustracción ilícita, es una medida efectiva para paliar dos posibles riesgos: por un lado, el desapego del menor respecto del progenitor que ha dejado atrás a consecuencia del traslado o retención; y por otro, la posible interferencia parental del progenitor sustractor induciendo en él una opinión desfavorable o negativa del progenitor sustraído ${ }^{61}$.

57. Que el interés del menor se establezca como límite para el contacto con la persona que solicita la restitución, supone asumir que tal contacto podría no ser conveniente ${ }^{62}$. Nuestra legislación es consecuente con ello, y probablemente, a tal razón, se contempla la medida antagónica al aseguramiento del contacto con el menor en el art. $158.5^{\circ}$ del Código Civil, que legitima al órgano jurisdiccional o al Ministerio Fiscal a dictar medidas de "prohibición de comunicación con el menor, que impedirá a los progenitores, tutores, a otros parientes o a terceras personas establecer contacto escrito, verbal o visual

${ }^{59}$ El art. 20.3 del Convención sobre los Derechos del Niño, adoptada por la Asamblea General de las Naciones Unidas el 20 de noviembre de 1989 (BOE núm. 313, de 31 de diciembre de 1990, en adelante) contempla medidas como "la colocación en hogares de guarda, la kafala del derecho islámico, la adopción, o de ser necesario la colocación en instituciones adecuadas de protección de menores".

${ }^{60}$ En este sentido, se pronuncian el art. 9.3 Convención sobre los Derechos del Niño y el art. 24.3 de la Carta de los Derechos Fundamentales de la Unión Europea (DOUE C 326, de 26 de octubre de 2012). Sobre la interpretación del Tribunal Europeo de Derechos Humanos, puede obtenerse una interesante síntesis jurisprudencial a partir de la STEDH de 17 de noviembre de 2015, asunto Bondavalli vs. Italy. Recuperado de: http://hudoc.echr.coe.int/eng?i=001-158942, pár. $72-73$ y la jurisprudencia citada en ella.

${ }^{61}$ Vid. T. Kruger. International Child Abduction. The Inadequacies of the Law, Hart Publishing, Portland, 2011, pp. 176-180.

${ }^{62}$ Vid. Fiscalía General del Estado. "Circular 6/2015, sobre Aspectos Civiles de la Sustracción Internacional de Menores", op. cit., p. 70. 
por cualquier medio de comunicación o medio informático o telemático, con respeto al principio de proporcionalidad". Esta medida es aplicable a la retención de un menor en España por remisión del art. 778 quáter 8 LEC de forma genérica al catálogo de medidas del art. 158 CC.

58. Esa prohibición de contacto la podríamos plantear cuando se apreciase grave riesgo para el menor. Un ejemplo sería en caso de darse una situación de violencia de género. En un reciente estudio de M. Pérez-Salazar Resano, P. Ortuño Muñoz y Mª T. Gonzalo Rodríguez, las autoras recomiendan que, en estos casos, se tengan en cuenta varios criterios para valorar el establecimiento, mantenimiento o suspensión del contacto con los menores, que se basan en la relevancia penal de la conducta del maltratador y sus efectos sobre la víctima, sobre el menor, y sobre los vínculos familiares ${ }^{63}$.

59. Otro factor de riesgo, de actualidad, lo encontraríamos en la crisis sanitaria causada por la pandemia de COVID-19, que ha llevado a que, a partir de la declaración del Estado de alarma, y ante los riesgos de contagio, se dictaran varios Acuerdos y Recomendaciones por los Juzgados de Familia de varias provincias judiciales, con criterios variables en cuanto al mantenimiento del contacto con los progenitores ${ }^{64}$.

\section{Medidas en caso de dictarse la restitución del menor (art. 27.5 R. 2019/1111)}

60. El art. 27.5 R. 2019/1111 dispone que: "Cuando ordene la restitución del menor, el órgano jurisdiccional podrá, en su caso, dictar medidas provisionales, incluidas las cautelares, de conformidad con el artículo 15 del presente Reglamento a fin de proteger al menor del riesgo mencionado en el artículo 13, párrafo primero, letra b), del Convenio de La Haya de 1980, siempre que el estudio y la adopción de dichas medidas no retrase indebidamente el procedimiento de restitución". Es decir, que con la resolución que ordena la efectiva restitución del menor, el Reglamento también permite adoptar medidas provisionales, incluidas las cautelares ${ }^{65}$, si concurren, según el Reglamento, una serie de requisitos (sin olvidar los condicionantes del art. 15).

61. El primero es la existencia de un grave riesgo para el menor. Este requisito invita a una reflexión. Uno de los propósitos del sistema complementario al CH 80 configurado, primero por el R. 2201/2003, y a futuro, por el R. 2019/1111, es garantizar que el menor sea restituido al Estado de su residencia habitual bajo la premisa de que las autoridades competentes en dicho Estado hayan adoptado todas las medidas que protejan al menor de un grave riesgo físico, moral o psíquico ${ }^{66}$. Por lo tanto, no debería existir, al amparo de ambos instrumentos internacionales, resolución alguna que ordene la restitución si existe peligro para el menor. Para cuando la restitución haya de hacerse efectiva, en teoría,

${ }^{63}$ Vid. M. Pérez-Salazar Resano, P. Ortuño Muñoz y Mª.T. Gonzalo Rodríguez. "Problemática específica de la custodia y de las relaciones parentales en casos de violencia sobre la mujer o sobre menores", en AAVV. Guía de criterios de actuación judicial en materia de custodia compartida, Consejo General del Poder Judicial, 2020. Recuperado de:

http://www.poderjudicial.es/cgpj/es/Temas/Ig

ualdad-de-Genero/Estadisticas--estudios-e informes/Estudios/Guia-de-criterios-de-actuacion-judicial-en-materia-de-custodia-compartida, pp. 208-211.

${ }^{64} \mathrm{Vid}$. F.F. Mateo Bueno. "Estado de Alarma: Recopilación por provincias de los acuerdos adoptados por los Juzgados de Familia”. Mateo Bueno. Abogado de Familia: Mis artículos. Recuperado de https://www.mateobuenoabogado.com/coronavirus-covid-19-acuerdos-juzgados-de-familia/ (Consultado el 2 de septiembre de 2020).

${ }^{65}$ El Considerando 46 R. 2019/1111 ofrece algunos ejemplos de posibles medidas: “...la decisión de que el menor siga residiendo con la persona que asume su cuidado efectivo o la determinación del modo en que deben tener lugar los contactos con el menor tras la restitución hasta que el órgano jurisdiccional del Estado de residencia habitual del menor haya dictado las medidas que considere apropiadas...".

${ }^{66} \mathrm{Vid}$. A. M. SÁnchez-Moraleda. “¿El Reglamento Bruselas II bis facilita el retorno del menor en caso de su traslado o retención ilícitos?” en A. MONGE FernáNDEZ (dir.). La sustracción internacional de menores desde una perspectiva multidisciplinar, JYB Bosch Editor, Barcelona, 2019, pp. 137-138 y 154. Aunque la autora compara el R. 2201/2003 con la Propuesta de Reforma de 2016, las conclusiones de su estudio se mantienen con la entrada en vigor del R. 2019/1111. 
el riesgo no debería existir, y consecuentemente, las medidas preventivas y cautelares del Estado de retención deben tener poca o ninguna efectividad.

62. Además, al momento de dictarse la restitución del menor, la actividad jurisdiccional del Estado requerido finaliza, por lo que al dictar las medidas provisionales, incluidas las cautelares, del art. 27.5, nos encontramos en una situación que enfrenta competencialmente al órgano jurisdiccional del Estado donde residía el menor antes del traslado o retención, que conoce del fondo del asunto, con el órgano jurisdiccional el Estado donde ha sido retenido, que sólo puede dictar medidas provisionales, incluidas las cautelares. Conforme al Considerando 31 R. 2019/1111, esto se traduce en una obligada transmisión de la competencia en favor de los tribunales competentes en cuanto al fondo: "Un órgano jurisdiccional que solo tenga competencia para adoptar medidas provisionales, incluidas las cautelares, debe, ante una demanda relacionada con el fondo del asunto, declararse de oficio incompetente si un órgano jurisdiccional de otro Estado miembro es competente para conocer del fondo del asunto en virtud del presente Reglamento" ${ }^{67}$.

63. Si se puede mantener lo anteriormente dicho, el resultado en la práctica sería un cierto vacío de utilidad de la norma. Sin embargo, todo apunta a que el art. 27.5 R. 2019/1111 debe leerse desde la intención de reforzar la confianza mutua entre los Estados Miembros de la siguiente manera: por exigente que sea la urgencia del asunto para dictar medidas cautelares, los tribunales del Estado de residencia habitual necesitan tiempo para decidir qué medidas pueden resultar eficaces para paliar el grave riesgo del menor. Por ello, el Reglamento prevé la eficacia provisional de las medidas dictadas en el Estado de retención del menor hasta que el órgano jurisdiccional del Estado de origen dicte sus medidas provisionales (Considerando 59 R. 2019/1111, in fine). Es decir, a cambio de confiar en que las autoridades del lugar donde residía el menor adopten las medidas adecuadas en su jurisdicción, dichas autoridades harán provisionalmente ejecutivas las medidas dictadas por las autoridades que han ordenado restituir al menor, asegurando a éstas que el menor es devuelto a un entorno seguro ${ }^{68}$.

64. Se precisa igualmente que "el estudio y la adopción de dichas medidas no retrase indebidamente el procedimiento de restitución". La referencia temporal, entendemos, son las seis semanas que se otorgan, bajo el nuevo Reglamento, para cada instancia y para la ejecución (arts. 24 y 28.2 R. 2019/1111).

65. El último de los requisitos al que vamos a referirnos no compromete la facultad para dictar medidas provisionales, incluidas las cautelares, pero sí su eficacia transfronteriza, por ello lo incluimos como un añadido a los anteriores. Según el art. 2.1.b) R. 2019/1111, para garantizar esa eficacia, se necesita "que el progenitor que solicita la restitución haya sido escuchado, o en su defecto, que haya sido notificado de la medida a adoptar con carácter previo a la ejecución". Se trata de una exigencia más relajada que la planteada en su día en el art. 48 de la Propuesta de 2016, en cuyo párrafo segundo se dis-

\footnotetext{
${ }^{67}$ El Considerando 31 R. 2019/1111 es receptor de la jurisprudencia europea en la STJUE de 9 de noviembre de 2010, asunto C-296/10, Purrucker II (ECLI:EU:C:2010:665), que niega la posibilidad de aplicar la excepción de litispendencia internacional en el caso de que el primer órgano jurisdiccional conozca de una solicitud de medidas cautelares conforme al art. 20 R. 2201/2003, y se interponga una demanda sobre el fondo ante el segundo órgano jurisdiccional, materialmente competente conforme al Reglamento. En este sentido, la regla de litispendencia del art. 20.2 R. 2019/1111 excepciona la regla prior in tempore, potior in iure, en caso de que la competencia de uno de los órganos jurisdiccionales se funde en el art. 15 R. 2019/1111.

${ }^{68}$ Tal es la filosofía de la Comisión, de acuerdo con el Informe de Impacto presentado en 2016. Vid. Comisión EuropeA. "Commission Staff Working Document Impact Assessment accompanying the document Proposal for a Council Regulation on jurisdiction, the recognition and enforcement of decisions in matrimonial matters and the matters of parental responsibility, and on international child abduction (recast)", op. cit., p. 43: "Provisional, protective measures with cross-border effect would enable the court of refuge to make itself, at least initially, an "adequate arrangement" to secure the protection of the child after his or her return", without awaiting such measures to be taken by the court of origin and thereby enable the court to order return more quickly. Indeed, it would also encourage the court of origin to take such measures, and thus facilitate coordination and cooperation between the court of refuge and the court of origin, and, thereby, it would help reduce the need for an order refusing return and further reduce delays".
} 
ponía que las disposiciones sobre reconocimiento y ejecución "no se aplicarán a las medidas provisionales, incluidas las cautelares, ordenadas por una autoridad sin que el demandado haya sido citado a comparecer". Aquí se denota un intento por establecer un nuevo equilibrio entre el derecho de audiencia de la persona que solicita la restitución (inexorable, según el art. 27.1 R. 2019/1111) y el interés superior del menor ante una situación de peligro para éste. Esa ponderación es favorable a proteger al niño, lo cual es razonable, sin dejar de lado la posibilidad de que la persona que solicita la restitución, mediante la puesta en conocimiento de la medida, tenga la oportunidad procesal, por medio de recursos, de hacer valer su punto de vista a posteriori.

66. En nuestra legislación, los arts. 778 quáter. 8 y 778 quinquies. 5 LEC, ambos en sus respectivos segundos párrafos, realizan una remisión al procedimiento de "medidas provisionales derivadas de la admisión de la demanda de nulidad, separación o divorcio" del art. 773 LEC. Dicho precepto, en su apartado tercero, exige, por remisión al art. 771 LEC la comparecencia de las partes, asistidas de abogado y procurador, así como del Ministerio Fiscal -dado que el interés del menor está presente- con carácter previo a la adopción de las medidas para intentar un acuerdo sobre las mismas o en su defecto, para que se pronuncien todos los comparecientes. A diferencia de lo que pretende el Reglamento, la única forma de ejecutar medidas sin comparecencia del progenitor demandado sería que éste voluntariamente no asistiera (art. 771.3 LEC, párrafo segundo).

\section{IV. ¿Existen medidas preventivas de la sustracción internacional de menores?}

67. Hasta ahora hemos planteado el estudio de las medidas provisionales, incluidas las cautelares, una vez se ha producido el traslado o retención ilícitos. Sin embargo, la mejor protección contra la sustracción internacional de menores, sin duda, es evitar que llegue a producirse. Prevenirla es una cuestión que depende de la perspicacia de las partes o del órgano jurisdiccional en la detección de la urgente necesidad de adoptarlas antes de que el riesgo aparezca o cuando es incipiente. En situaciones de crisis matrimonial transfronteriza, de judicialización de ésta o incluso en situaciones supuestamente pacíficas sin aparentes conflictos, el riesgo de sustraer al menor puede llegar a manifestarse ${ }^{69}$. A nivel convencional, europeo y nacional, podemos apreciar ciertas iniciativas que dan lugar a concluir que existe un esfuerzo por evitar que la sustracción de menores se materialice. Presentaremos las iniciativas en el orden indicado.

\section{Recomendaciones para la prevención de la sustracción internacional de menores a nivel con- vencional}

68. A nivel convencional, la Conferencia de La Haya de Derecho Internacional Privado es consciente de esta eventualidad, y como prueba de ello, tiene publicada una Guía de Buenas Prácticas sobre medidas preventivas. Grosso modo, de su contenido puede extraerse una clasificación entre medidas preventivas de acción y medidas preventivas de reacción. Dentro de la primera categoría, y pensando precisamente en las crisis familiares, se propone el fomento de la mediación, el establecimiento de medidas que eviten la sustracción en las resoluciones que resuelven sobre las crisis matrimoniales, el respeto a los derechos de visita, o la eficacia extraterritorial de las resoluciones en materia de custodia y visita. En cuanto las medidas de reacción, se recomiendan las limitaciones administrativas a la movili-

${ }^{69}$ Vid. T. KRUGER. International Child Abduction. The Inadequacies of the Law, op. cit., p. 224. La autora enuncia un catálogo de situaciones indiciarias que permiten advertir un posible riesgo de sustracción ilícita: situaciones referidas a la existencia de una crisis familiar, a la intención más o menos manifiesta del progenitor de llevarse al menor consigo, o a determinadas acciones que evidencian que el progenitor potencialmente sustractor se está desvinculando personal o patrimonialmente del Estado de residencia habitual del menor y estableciéndose en otro Estado. Aun así, recalca que muchas veces esos indicios no son perceptibles o que siéndolos, los esfuerzos por prevenir que el menor sea trasladado o retenido han sido en balde. Vid. ibíd. pp. 214-216. 
dad transfronteriza del menor, como las restricciones a la emisión de pasaportes y visados, garantizando el consentimiento de ambos progenitores y la comunicación entre Autoridades. Finalmente, la Guía también apunta a plantear la promulgación medidas disuasorias, tales como la prestación de fianzas, la facilidad de acceso a los tribunales o la tipificación de la sustracción como ilícito penal ${ }^{70}$.

\section{La prevención de la sustracción internacional de menores en la Unión Europea}

69. Pasando al ámbito europeo, hemos de señalar que la Unión Europea responde a las recomendaciones del $\mathrm{CH} 80$ en cuanto a las medidas preventivas de acción. En concreto, realza la apuesta por acudir a la mediación entre otros medios de resolución alternativa de conflictos (art. 25 R. 2019/1111). Aunque más bien esta medida, tal y como está planteada en el Reglamento, no es propiamente preventiva de la sustracción, sino más bien, del litigio en torno a ella ${ }^{71}$. Los órganos jurisdiccionales tendrán, según el nuevo precepto, la obligación de invitar a las partes, siempre que la situación lo permita, a solucionar el conflicto dimanante de la sustracción internacional de menores dentro del ámbito familiar, auxiliados por profesionales especializados, y fuera de los tribunales. Varios autores insisten en la conveniencia de esta vía, además de por los costes económicos, temporales y psicológicos de sustanciar litigios, por la necesidad de que las relaciones familiares con el menor perduren en el tiempo de forma pacífica, entre otras muchas ventajas ${ }^{72}$.

70. Continuando con las previsiones europeas, el R. 2019/1111 ha suprimido el exequátur a las resoluciones que deciden la restitución de los menores y, junto a ellas, a las medidas cautelares que se dicten con ocasión de esa devolución. Esta medida permitirá prevenir que, con ocasión de un doble traslado o una sustracción itinerante a varios Estados, se hayan de sustanciar sucesivos procedimientos de restitución del menor que complicarían seriamente el retorno. La ejecución directa también alcanza, en general, a cualquier resolución sobre la responsabilidad parental (arts. 30.1 y 34.1 R. 2019/1111), con lo cual, a efectos de hacer valer el derecho de custodia vulnerado por el progenitor sustractor, el nuevo régimen del Capítulo IV del R. 2019/1111 facilita mucho los trámites. Otras dos previsiones importantes son la ejecución provisional de las resoluciones de restitución pese a la interposición de recursos, que

70 Conferencia de La Haya de Derecho Internacional Privado, "Guía de buenas prácticas en virtud del Convenio de La Haya del 25 de octubre de 1980 sobre los aspectos civiles de la sustracción internacional de menores - Tercera Parte - Medidas de prevención", op.cit., pp. 14 y 16-33.

${ }^{71}$ P. OReJUdo Prieto DE Los Mozos resalta que, como medida preventiva, la mediación "permitiría alcanzar acuerdos que son acatados de forma voluntaria la generalidad de las veces, al satisfacer en gran medida los intereses de todos los implicados. De ahi que, empleada en el momento en que la pareja entra en conflicto, la mediación pueda impedir que los menores sean trasladados o retenidos de forma ilicita", "Mediación y Sustracción Internacional de Menores", en F. AldECOA LuZÁRRAGA y J.J. Forner Delaygua (dirs.) y E. GonzÁlez Bou y N. González Viada (Coords.), La Protección de los niños en el Derecho Internacional y en las relaciones internacionales. Jornadas en conmemoración del 50 aniversario de la Declaración Universal de los Derechos del Niño y del 20 aniversario del Convenio de Nueva York sobre los Derechos del Niño, Marcial Pons, Madrid, 2010, pp. 370-371. En el mismo sentido, vid. A. HernÁndez Rodríguez. "Mediación y Secuestro Internacional de Menores: Ventajas e inconvenientes", CDT, Vol. 6, núm. 2 (2014), pp. 130-146, pp. 141-142; y C. Chéliz IngLÉs. La sustracción internacional de menores y la mediación. Retos y vias prácticas de solución, Tirant Lo Blanch, Valencia, 2019, pp. 173-174.

${ }^{72}$ Vid. C. ChéLIz Inglés., La sustracción internacional de menores y la mediación. Retos y vías prácticas de solución, op. cit., pp. 166-175. A. Marín Velarde y F. Moreno Mozo. "El interés superior del menor y su relevancia en la sustracción internacional de menores", en A. Monge FernÁNDEZ (dir.). La sustracción internacional de menores desde una perspectiva multidisciplinar, JYB Bosch Editor, Barcelona, 2019, pp. 237-239, consideran una ventaja para tratar la sustracción, la aplicación de los principios orientadores de la mediación, tales como voluntariedad, imparcialidad, neutralidad, flexibilidad, los cuales se enuncian tanto en la legislación nacional como en la autonómica especificada infra. También son interesantes los trabajos de A. HernÁndez RodríGuez. "Mediación y Secuestro Internacional de Menores: Ventajas e inconvenientes", op. cit., p. 136; C. Carrillo Lerma. "Mediación Familiar Internacional y Sustracción Internacional de menores", BARATARIA. Revista Castellano-Manchega de Ciencias Sociales, núm. 19, 2015, p. 187, C. AzcÁrraga Monzonís. "Mediación en Conflictos Internacionales: Aportaciones desde la Práctica Convencional de La Haya", en R. Grasa Hernández, A. Blanc Altemir y P. Diago Diago. La aplicación de la mediación en la resolución de conflictos en el Mediterráneo (Iniciativa para la Mediación en el Mediterráneo). Recuperado de: http://www.exteriores.gob.es/Portal/es/SalaDePrensa/Multimedia/Publicaciones/Documents/ LaAplicacióndelaMediación.pdf, p. 252. 
permitirá, si el interés superior del menor lo exige, agilizar la devolución del menor al Estado de origen (art. 27.6 R. 2019/1111) ${ }^{73}$ y la prohibición de la ejecución parcial de las decisiones de restitución que necesitan acompañarse de medidas cautelares contra cualquier grave riesgo (art. 53.3 R. 2019/1111).

71. En cuanto las medidas de reacción sobre movilidad, en la UE cabe destacar el papel del Reglamento (CE) $n^{o}$. 562/2006 del Parlamento Europeo y del Consejo, de 15 de marzo de 2006, por el que se establece un Código comunitario de normas para el cruce de personas por las fronteras (Código de fronteras Schengen ${ }^{74}$, cuyo Anexo VII regula un régimen específico para el paso fronterizo de menores: cuando están acompañados, se ha de comprobar que el sujeto que lo acompaña ostenta la patria potestad y que no está desplazando al menor sin el consentimiento del otro progenitor (apartado 6.2 R. 562/2006), y en el caso de menores no acompañados, también ha de comprobarse documentalmente que el abandono del territorio no se realiza contra la voluntad de quienes ostentan la patria potestad (apartado 6.3 R. 562/2006) ${ }^{75}$. Asimismo, el Reglamento plantea la aplicación analógica del régimen de control de las fronteras exteriores (entre Estado Miembro y no Miembro), para el caso de menores que las crucen, conforme al apartado 6.1 R. 562/2006, bien sea para entrar a un Estado Miembro desde un tercer Estado o viceversa.

72. Señalar por último que, aunque no existe ninguna suerte de "tipo delictivo europeo" de sustracción internacional de menores, sí hay que destacar que el TJUE se ha pronunciado recientemente sobre la necesaria adecuación normativa del delito de sustracción de menores con el derecho de los ciudadanos europeos a circular y residir libremente en el territorio de los Estados Miembros, en su vertiente de prohibición de discriminación por nacionalidad en la STJUE de 19 de noviembre de 2020, asunto C-454/19, $Z W^{76}$. La cuestión prejudicial ha concernido al art. 235 del Strafgesetzbuch o Código Penal alemán, que exige la existencia de "fuerza, amenaza de daño grave o engaño" para las sustracciones nacionales, pero no para las sustracciones internacionales, donde basta el simple traslado para apreciar el delito. El TJUE reconoce el efecto disuasorio que puede tener el delito de sustracción internacional de menores para evitar que se produzcan y proteger a los menores. Ahora bien, pese a ello, niega que la tipificación del Código Penal alemán, fuera conforme con el art. 21 del Tratado de Funcionamiento de la UE, porque se basaba en "la presunción de que es imposible o excesivamente difícil obtener el reconocimiento, en otro Estado miembro, de una resolución judicial relativa a la custodia de un menor y, en caso de sustracción internacional de este, a su restitución inmediata", argumento que al TJUE le resulta contrario al principio de confianza mutua que inspira al R. 2201/2003.

\section{Las medidas preventivas en la legislación española}

73. A nivel interno, la legislación española contiene un catálogo numerus apertus de medidas preventivas para evitar la sustracción ilícita en el art. $158.3^{\circ} \mathrm{CC}$. Entre las medidas que se concretan,

\footnotetext{
${ }^{73}$ La regla de ejecución provisional tiene vocación de excepcionalidad; su aplicación debe valorarse conforme al interés superior del menor (Considerando 47 R. 2019/1111) y también según las exigencias de urgencia que requieran una rápida restitución (Considerando 66 R. 2019/1111). Con todo, también es posible que lo idóneo sea suspender la ejecución de la resolución, en especial cuando la impugnación de la eficacia de las resoluciones obedezca a la concurrencia de causas de denegación de la ejecución o de revocación de los certificados relativos a las resoluciones privilegiadas, cuando no haya transcurrido el plazo interposición del recurso, o cuando pueda apreciarse una causa de grave riesgo para el menor. Vid. Considerandos 67 y 68 , así como los arts. 33, 44, 56, 57 y 63 del R. 2019/1111. En España se mantiene la prohibición de la ejecución provisional de las resoluciones sobre restitución de menores (art. 525.1. $1^{\circ}$ LEC), lo cual necesitará ser modificado. No obstante, en opinión de F-.J. Forcada Miranda. Comentarios prácticos al Reglamento (UE) 2019/1111. Competencia, reconocimiento y ejecución de resoluciones en materia matrimonial, responsabilidad parental y sustracción internacional de menores, op. cit., pp. 251-252, si los plazos del recurso de apelación son suficientemente expeditivos, sería innecesaria la ejecución provisional.

${ }^{74}$ DOUE núm. L 105 de 13 de abril de 2006.

${ }^{75}$ Vid. M.C. ChÉLIz InGLÉs. La sustracción internacional de menores y la mediación. Retos y vías prácticas de solución, op. cit. pp. 24-25 y notas 10-12.

${ }^{76}$ STJUE de 19 de noviembre de 2020, asunto C-454/19, ZW (ECLI:EU:C:2020:947), pár. 43-50.
} 
se encuentran la "prohibición de salida del territorio nacional salvo autorización judicial previa", la "prohibición de expedición del pasaporte al menor o retirada del mismo si ya se hubiera expedido", y el "sometimiento a autorización judicial previa de cualquier cambio de domicilio del menor". Interesa resaltar que estas medidas pueden dictarse en cualquier momento del procedimiento de sustracción del menor (art. 778 quinquies. 8 LEC), e igualmente en procesos matrimoniales, como prevén los arts. 103.1.III CC y $771 \mathrm{LEC}^{77}$. El simple hecho de que con ocasión de las crisis conyugales ya puedan entrar a operar estas medidas nos da cuenta del compromiso del legislador español con garantizar la evitación a toda costa de un traslado ilícito. Para mayor apoyo de esta afirmación, incluso resultaría posible solicitar una tutela cautelar provisionalísima con carácter previo a la interposición de la demanda de nulidad, separación o divorcio, conforme al art. $104 \mathrm{CC}$, aplicando las medidas del art. 103.1.III CC para prevenir la sustracción ilícita; si bien, esta tutela previa a la demanda se concreta en su provisionalidad estableciendo un plazo de 30 días para accionar ante los tribunales.

74. En España, la mediación también se encuentra regulada para los procesos de restitución de menores en el art. 778 quinquies. 12 LEC. Como ocurre con el Reglamento, la mediación no se plantea como forma de prevención de la sustracción, sino una vez se produce, como alternativa a encauzar judicialmente la respuesta jurídica de restitución ${ }^{78}$. Como indica el precepto, el Juez puede invitar a las partes en cualquier momento del proceso a solucionar por esta vía la controversia surgida por la sustracción ilícita, o bien solicitarlo las partes. Se prevé además que la mediación no sea utilizada como estrategia dilatoria de una decisión sobre la devolución, buscando concentrar el alcance del acuerdo en el menor número de sesiones posible, y limitando en todo caso la suspensión del proceso a seis semanas, frente a la regla general de suspensión por sesenta días del procedimiento del art. 19.4 LEC. El resultado de la mediación es un acuerdo que ha de ser homologado por el Juez y que, por lo tanto, dará como resultado un auto (art. 206.1. $2^{\circ}$ LEC), que se someterá, a efectos de su reconocimiento y ejecución transfronterizas, a las reglas de eficacia extraterritorial de resoluciones judiciales del Capítulo IV del R. 2019/1111.

75. Sobre la cuestión de la movilidad extraterritorial del menor, como bien recuerdan $\mathrm{M}^{\mathrm{a}}$. C. ChÉLIZ Inglés y Ma . A. Martín Huertas, está vigente en nuestro país el Real Decreto 411/2014, de 6 de junio, por el que se modifica el Real Decreto 896/2003, de 11 de julio, por el que se regula la expedición del pasaporte ordinario y se determinan sus características ${ }^{79}$. Este Real Decreto modificó el art. 4.2 del Real Decreto 896/2003, exigiendo a partir de la reforma que quienes ostentaren patria potestad sobre el menor deban prestar su consentimiento ante el funcionario competente para la expedición de un pasaporte al menor, acreditando documentalmente su identidad y la relación de parentesco o tutela. Además, deben corroborar que el ejercicio de la patria potestad no se encuentra limitado, y en caso de estarlo, que se ha suplido con autorización judicial ${ }^{80}$.

76. Por último, no hay que olvidar que la sustracción internacional de menores constituye un delito tipificado en el art. 225 bis de nuestro Código Penal. Nuestro tipo penal es conforme con la re-

${ }^{77}$ Vid. Ma . A. Martín Huertas. "El Convenio de La Haya de 1980. Las medidas preventivas establecidas por el legislador español en la sustracción internacional de menores", op. cit. pp. 119-122.

${ }^{78}$ C. GonzÁlez Beilfuss. "La sustracción de menores en el nuevo Reglamento 2019/1111”, en A.A.V.V., Relaciones Transfronterizas, Globalización y Derecho. Homenaje al Profesor Doctor José Carlos Fernández Rozas. Editorial Aranzadi, Pamplona, 2020, p. 396, apunta como diferencia que la promoción de la mediación es facultativa en la LEC e imperativa en el R. 2019/1111, y plantea que España podría prever una fase previa al litigio, para valorar la posibilidad de que el caso concreto sea resuelto por mediación. Ello será efectivo siempre y cuando exista cierta predisposición de las partes a alcanzar un acuerdo, que podría contrastarse informando sobre las ventajas de la mediación y comprobando si los progenitores estarían dispuestos a solucionar el conflicto por esta vía alternativa al litigio.

${ }^{79}$ BOE núm. 154, de 25 de junio de 2014. Vid. M. C. ChÉLIz InGLÉs. La sustracción internacional de menores y la mediación. Retos y vías prácticas de solución. op. cit., pp. 24-25 y nota 12 y Ma.A. MARTín HuerTAs. "El Convenio de La Haya de 1980. Las medidas preventivas establecidas por el legislador español en la sustracción internacional de menores", op. cit. p. 121 , nota 68

${ }^{80} \mathrm{Con}$ anterioridad a la reforma, bastaba que quien ostentaba la patria potestad acreditara su propio consentimiento y que su ejercicio no estaba limitado, o en caso de estarlo, que se ha obtenido autorización judicial. 
ciente jurisprudencia del TJUE, pues el supuesto de hecho que origina el delito no presenta exigencias específicas si la sustracción se produce dentro o fuera de las fronteras de nuestro Estado. Sí se aprecia diferencia en la cualificación de la sanción que castiga uno y otro tipo de sustracción: si la sustracción es nacional, se impone la pena de dos a cuatro años de prisión y la inhabilitación especial para el ejercicio de la patria potestad de cuatro a diez años; y en caso de ser internacional, las penas se imponen en su mitad superior, es decir, de tres años y un día a cuatro años de prisión y de siete años y un día a diez años de inhabilitación. Ello denota en el legislador cierta ambición especial por disuadir la sustracción internacional ${ }^{81}$. Como contrapartida, también se pretende persuadir al sustractor de que ceje en su actitud y devuelva al menor cuanto antes al Estado de su residencia habitual, y para ello, prevé la exención de la pena si comunica el paradero del menor en las veinticuatro horas siguientes y lo devuelve inmediatamente, o si la ausencia no es superior a veinticuatro horas; así como la reducción de la pena a un rango de entre seis meses a dos años de prisión si devuelve al menor sin comunicar previamente dónde se encuentra éste (Art. 225 bis.4 CP).

77. En definitiva, la presentación de todas las medidas señaladas nos permite concluir que, tanto a nivel convencional, como europeo y nacional, se pueden plantear mecanismos preventivos contra el riesgo de una sustracción internacional de menores ${ }^{82}$.

\section{Conclusiones}

78. Toda protección es poca cuando el menor se encuentra secuestrado. En el marco de esa protección, no sólo interesa que el menor sea efectivamente restituido a su hogar. Esa devolución es resultado de un procedimiento que, por breve que se pretenda, va a consumir cierto tiempo. Mientras tanto, la vida del menor sigue, y además en un entorno al que no está habituado, y alejado del progenitor con el que normalmente se desenvuelve en su vida cotidiana. Por ello, el esfuerzo de las autoridades judiciales ante la sustracción internacional de un menor es doble: por un lado, garantizar la inmediata restitución; pero igualmente, hasta que esa decisión llegue, se han de asegurar de que el menor goce de la mayor estabilidad y la menor perturbación. De ahí la importancia de que exista un régimen bien configurado de medidas provisionales, incluidas las cautelares.

79. En este sentido, las aclaraciones con las que el R. 2019/1111 suple el silencio del CH 80 en la materia (desde el régimen general del art. 15 al especial de los apartados segundo y quinto del art. 27, además de los Considerandos que acompañan con su interpretación), son dignas de alabanza. Para mayor celebración, los operadores jurídicos españoles cuentan con un régimen en nuestra LEC que se anticipa en muchos aspectos a las exigencias y las recomendaciones internacionales, de tal suerte que, para cuando el nuevo Reglamento comience a aplicarse, no tendremos especiales problemas en alinearnos con su articulado sobre el procedimiento de restitución. Esto no quiere decir que nuestro vanguardismo jurídico deba cegarnos ante la realidad: la sustracción internacional de menores sigue siendo una realidad en nuestro país, como en cualquier otro, y seguramente las soluciones jurídicas hayan de seguir mejorando de cara al futuro.

\footnotetext{
${ }^{81}$ Pese a ello, España mantiene una tendencia por encima de las 300 infracciones por delito de sustracción internacional de menores, siendo especialmente alto el dato de 2019, con 369 infracciones penales. Vid. Ministerio del Interior. Centro Nacional de Desaparecidos de España. “Informe Anual sobre Personas Desaparecidas en España, 2020”. Recuperado de: http://www. interior.gob.es/documents/10180/11389243/Informe+Personas+Desaparecidas+2020.pdf/19fca169-a401-432e928ca88d23708d 04, p. 41.

${ }^{82}$ Ello sin perjuicio de que la doctrina haya planteado otro tipo de medidas que ayudarían a la prevención. Por ejemplo, configurar registros de menores desaparecidos, o que contengan información acerca de las facultades que los progenitores tienen restringidas en el ejercicio de la patria potestad respecto de sus hijos, o la creación de listados oficiales se pueda inscribir a los menores para que las autoridades tengan constancia del riesgo de sustraerlos del territorio nacional veden la posibilidad de dejarles salir del país o impidan expedirles un pasaporte. Vid. T. Kruger. International Child Abduction. The Inadequacies of the Law, op. cit., pp. 220-221 y M. L. Soто RodríguEz. "La sustracción de menores", Diario La Ley, Núm. 8331, Sección Doctrina, 12 de Junio de 2014, Año XXXV, Ref. D-193, p. 11.
} 
80. Los esfuerzos tienen que darse también en aras a evitar que este fenómeno tan traumático en las crisis familiares se produzca. El Derecho de la UE contiene ciertas iniciativas que permiten minorar el agravamiento de la sustracción una vez producida. No obstante, se podría afianzar aún más un enfoque preventivo, aprovechando que existen instrumentos internacionales al respecto. Por ejemplo, podría extenderse en una futura reforma el empleo de la mediación no sólo a los procedimientos de restitución, sino también a cualquier procedimiento sobre crisis matrimonial o responsabilidad parental, con carácter general. También sería interesante que la complementariedad entre el R. 2019/1111 y el CH 80 comprendiera la cooperación entre Autoridades Centrales. E igualmente, sería positivo que se establecieran sinergias con el R. 562/2006 en materia controles transfronterizos de desplazamientos de menores sin autorización de sus progenitores.

81. La situación del Reino Unido merece unas breves líneas para cerrar este estudio. Se trata del segundo Estado parte del CH 80 que más solicitudes de restitución registró en el año $2015^{83}$, de las cuales más de la mitad provenían de Estados Miembros de la $\mathrm{UE}^{84}$, con lo cual es relevante mantener una relación de cooperación consolidada con este Estado. Ocurre que desde el 30 de enero de 2020 ha dejado de ser Estado Miembro de la Unión Europea, y a partir del 31 de diciembre de 2020, dejará de aplicar sus actos legislativos $^{85}$, con lo que las novedades del R. 2019/1111 quedan excluidas para las sustracciones que impliquen a este Estado. No obstante, gracias a que el Reino Unido es parte del CH 80, se podrá garantizar cierta continuidad en las relaciones internacionales, con el propósito de combatir la sustracción internacional de menores ${ }^{86}$. Del mismo modo, la inaplicación del nuevo Reglamento en el Reino Unido puede quedar suplida por el Convenio relativo a la competencia, la ley aplicable, el reconocimiento, la ejecución y la cooperación en materia de responsabilidad parental y de medidas de protección de los niños, hecho en La Haya el 19 de octubre de $1996^{87}$.

${ }^{83} \mathrm{Vid}$. N. Lowe y V. Stephens. Part I - A statistical analysis of applications made in 2015 under the Hague Convention of 25 October 1980 on the Civil Aspects of International Child Abduction - Global report, Recuperado de: https://assets. hcch.net/docs/d0b285f1-5f59-41a6-ad83-8b5cf7a784ce.pdf, p. 6, pár. 34. Fueron un total de 261 solicitudes registradas por las Autoridades Centrales inglesas en 2015.

${ }^{84} \mathrm{Vid}$. N. Lowe y V. Stephens. Part III - A statistical analysis of applications made in 2015 under the Hague Convention of 25 October 1980 on the Civil Aspects of International Child Abduction - National report, Recuperado de: https://assets. hcch.net/docs/6ca61ff3-5ca6-4fbe-a79a-cb6e7485f4b0.pdf, p. 131. Se ofrecen un cuadrante de la distribución por Estados del origen solicitudes registradas. Aunque no ofrecen el dato directo, si se suman las provenientes de Estados Miembros de la UE, se obtiene un total de 177 solicitudes, lo que supone un $68,58 \%$ del total.

${ }^{85}$ Los arts. 67 y 126 del Acuerdo sobre la retirada del Reino Unido de Gran Bretaña e Irlanda del Norte de la Unión Europea y de la Comunidad Europea de la Energía Atómica (DOUE núm. C 384I, de 12 de noviembre de 2019) mantienen la vigencia de los actuales actos legislativos de la Unión Europea hasta el 31 de diciembre de 2020.

${ }^{86}$ Recientemente, la Dirección General de Justicia y Consumo de la Comisión Europea ha publicado un documento que reseña la relación jurídica entre el Reino Unido y la Unión Europea antes y después de que concluya el período transitorio establecido en el Acuerdo de Retirada. En lo que se refiere al Derecho de Familia, el R. 2201/2003 seguirá siendo aplicable para el reconocimiento y ejecución de resoluciones y acuerdos formalizados antes del 31 de diciembre de $2020 \mathrm{y}$, para procedimientos posteriores, se habrá de estar a los Convenios bilaterales y multilaterales suscritos por Reino Unido, y en su defecto, aplicará su ley nacional. Al respecto, la Dirección recuerda que el CH 80 está suscrito por este Estado. Vid. EuropeAn Commission. Directorate-General Justice and Consumers. "Notice to Stakeholders. Withdrawal of the United Kingdom and EU rules in the field of Civil Justice and Private International Law”. Brussels, 27 August 2020 REV2. Recuperado de: https://ec.europa.eu/ info/sites/info/files/brexit_files/info_site/civil_justice_en.pdf, pp. 6 y 10, y nota 43.

${ }^{87}$ BOE núm. 291, de $\overline{2}$ de diciembre de 2010. 